Review

\title{
The Triple Immune Argument; Surveillance/Evasion/ Senescence and the Increased Incidence of Acute Myeloid Leukemia Observed with Age
}

\author{
${ }^{1,2}$ Manar M. Ismail \\ ${ }^{1}$ Department of Laboratory Medicine, Faculty of Applied Medical Science, Umm Al-Qura University, KSA \\ ${ }^{2}$ Department of Clinical Pathology, National Cancer Institute, Cairo University, Egypt
}

Article history

Received: 12-11-2017

Revised: 06-12-2017

Accepted: 20-12-2017

Email: manarismail4@yahoo.com

\begin{abstract}
AML originates from genetic insults of hematopoietic stem and progenitor cells (HSPCs/HSCs) that was identified earlier as leukemia stem cells (LSCs). In quiescent state, trafficking immune cells are crucial for eradication of aberrant clones and obtaining balance between proliferation and apoptosis to maintain HSCs pool. Regulatory T-cells shield the HSCs from the inflammatory reactions by suppressing $\mathrm{T}$ - and B- cells. Cancer immunoediting characterize the interaction between the tumor cells and the immune system during cancer evolution. Both branches of the immune system; innate and adaptive can identify AML blasts, eliminating them completely or keeping a balance state that prevents tumor excrescence. However, the AML blasts are struggling to survive and induce many evasion mechanisms ranged from suppression of natural killer and $\mathrm{T}$ cytotoxic cells up to the support of suppressor cells and creating a tumor permissive microenvironment. Upon aging, the immune system is restructured in a process termed immunosenescence. The most sticking event in immunosenescence is thymic involution with reduced T-cell output and diversity that will affect the immune surveillance properties, in addition to inflammaging that prepare a convenient environment for the evolution of AML. In this age-impaired immunity background, together with the other age related changes occur in HSPCs and bone marrow microenvironment would initiate and promote the development of AML that is indeed observed in older patients. Realizing this relation would help in proper choice of therapy and the development of new lines of immunotherapy against this difficult disease in that critical age.
\end{abstract}

Keywords: Aging, AML, Immune Surveillance, Immunevasion, Immunosenescence, Inflammaging

\section{Introduction}

Aging and development of malignancies are considered to be interrelated biological phenomena. However, there is no direct causative relation and the two processes seems to be contradictory (Bonafe et al., 2011). Aging is characterized by organ damage, wastage and decline in tissue regeneration (Granger et al., 2016). Contrarily, proliferation, resistance to apoptosis and acquisition of novel aberrant functions are hallmarks of cancer (Campisi, 2013). Lately, four new cancer criteria were proposed: Capability to escape cleverly from the immune surveillance, existence of inflammation, inclination to genomic instability and uncontrolled metabolism (Hanahan and Weinberg, 2011).

The incidence of cancers in the above 65 age group is $>60 \%$ of the newly diagnosed cases and the death rate due to malignancy is more than $70 \%$ (Fulop et al., 2010). This high incidence copes with the age-associated deterioration of the immune function and its capacity for immune surveillance that adds more fuel to the potentially carcinogenic and transformational insults to which an elderly patient already exposed to (Sportès and Hakim, 2009). The complex interaction between the 
malignant cells, the stromal cells and the immune cells modulates the process of cancer pathogenesis (Yaqub and Aandahl, 2009). There is a substantial series of proofs entails the wear out of immunity with senility, a phenomenon named immunosenescence. In aging, both branches of the immune system are distorted and a low grade inflammation evolves. These factors participate in increased tumorigenesis. Perception of the immunosenescence role in the evolution of malignancies and assistance of cancer advancement to critical stages could help with superior medical support and treatment in the elderly (Fulop et al., 2013).

The hematopoietic system in the BM is an ideal organ to study the relationship between malignancy and aging of the immune system being the location where the immune cells develop and interact with the malignant blasts. Some leukemias show increased incidence with aging (Rossi et al., 2007). In elderly people, B-chronic lymphocytic leukemia is the commonest type of chronic leukemia (Chiorazzi et al., 2005), while acute myelogenous leukemia (AML) is considered the recurrent type of acute leukemia (Pollyea et al., 2011). More than $60 \%$ of the newly diagnosed AML cases are above the age of 60 with a median age 68 years (NCI, 2017).

In this study we hypothesize that immune frailty associated with aging termed immunosenescence is a central factor in the evolution of AML in the aged population that together with the aged BM microenvironment and hematopoietic stem cell (HSC) complete the circle and start the disease. The relevance of the immune pathophysiology in context to the emergence of AML in the elderly including surveillance, immune evasion, senescence and inflammation are going to be highlighted in this review with a special reference to the clinical relevance of this relation.

\section{AML and Aging}

Hematopoietic failure is a hallmark of myeloid disorders particularly AML (Schroeder et al., 2016). AML originates from genetically defective hematopoietic stem and progenitor cells that were termed previously as leukemic stem cells (LSCs) or Cancer Stem Cells (CSCs) (Wang et al., 2017).

Normal stem cell function is closely related to the embracing cells in the surrounding milieu; named "stem cell niche" (Orford and Scadden, 2008; Carlesso and Cardoso, 2010), that consists of macrophages and stromal cells (Ehninger and Trumpp, 2011; Gyorki et al., 2009), the stromal cells are arranged into endosteal and vascular niche according to their anatomical locations. The core difference between the vascular and the endosteal niches is the oxygen content. HSC lies mainly in the endosteal niche that has a lower oxygen tension. When the HSC are stimulated by growth factors (e.g., granulocyte-macrophage colony-stimulating factor), interleukins (e.g., IL-3, IL8, IL-7 and IL-12), chemokines (e.g., CXCL12) and flt-3 ligand, they move towards the vascular niche. In the vascular niche higher oxygen supply enables cells to recommence their cell cycle and proceed to mitosis and cellular differentiation occurs. Afterwards, HSCs return to endosteal niche. The HSCs mobilization between endosteal and vascular niche is compulsory for hematopoietic balance (Iwasaki and Suda, 2010). HSCs are under control of cytokine network responsible for their maturation, pluripotency and interaction with immune cells. In quiescent state, trafficking of the immune cells is crucial for eradication of aberrant clones of HSCs and maintenance of equilibrium between proliferation and apoptosis to keep the HSCs pool constant (Giles et al., 2016). Regulatory $\mathrm{T}$ cells (Treg) in the bone marrow microenvironment (BMM) are prevailing to shield them from the annoying inflammatory reactions by suppressing both $\mathrm{T}$ and $\mathrm{B}$ cells (Camacho et al., 2017).

Hypoxia is a main feature of the endosteal niche; hypoxia reduces the flow of extracellur fluid that will reduce the exposure of HSC to the harmful toxins and proinflammatory cytokines that can promote cancer development (Eliasson et al., 2010). Additionally, hypoxia regulates HSC self-renewal as it potentiates cellular turnover, which reduces the accumulation of genetic damage that mostly ends in cancer evolution (Takubo et al., 2010). In the aged BMM, the HSCs reside away from endosteum that would increase oxidative insult to the DNA with subsequent augmentation of mutation (Takubo et al., 2010; Henry et al., 2011). Moreover, the adipose tissue reacts by increasing lipolysis as a metabolic disturbance in old age, with increases free fatty acid oxidation and ATP consumption. Thus, maintains a stressful BMM that represses HSCs and initiate resistance to chemotherapeutic agents (Silberstein et al., 2016).

In an aged BMM, the human HSCs prefer being differentiated into the myeloid lineage and became more clonal. Furthermore, the HSC clones are supposed to carry disease-inducing genetic and epigenetic changes. These two factors entail a higher risk for development of age related clonal hematopoietic disease, such as myelodysplastic syndrome, myeloproliferative disorders, or AML. The aged BMM may preferentially chose the senile HSC clones as a consequence of the changes that accompany aging (Pang et al., 2017).

Once the LSCs originated from mutated HSCs, they start to show considerable hostile features (Zhang et al., 2015). LSCs modulate BMM and participate in reprogramming of the LSC niche into a malignant niche that favors malignant cell survival and proliferation (Pleyer et al., 2016; Li and Neaves, 2006) and anticipate multiple pathways to evade immune response (Ashley et al., 2013). 


\section{Immune Surveillance in AML}

Cancer immunoediting signifies the interaction between the immunological and malignant cells during the state of neoplasm evolution. This hypothesis describes three consists of three consecutive stages: (i) Elimination that involves complete effacement of malignant cells, (ii) Equilibrium where the evolution of an immune- reluctant malignant clone arises and (iii) Escape where the tumor cells have elaborated strategies to evade immune detection or destruction (Kim et al., 2007).

The antileukemic immune effect is evident after allogeneic hematopoietic stem cell transplantation (Cooley et al., 2010) where the donor immune cells namely natural killer (NK) cells and cytotoxic $\mathrm{T}$ lymphocytes (CTLs) perform anti leukemic effect (Godder et al., 2007).

Both branches of the immune system; innate and adaptive can identify AML blasts, eliminating them completely or keeping a balance state that prevents tumor outgrowth (Schreiber et al., 2011; Lion et al., 2012). Despite the fact that most of the immunological cells participate in immune surveillance, NK cells are considered the essential effector cells from the innate system and the $\mathrm{T}$ cells are the indispensable cell from the adaptive system.

\section{Innate Immune Response}

The dendritic cells (DCs) are a fundamental link between innate and adaptive systems (Rainham et al., 2010). They are central in tumor antigen presentation to the $\mathrm{T}$ cells. Also, they commence and organize antigen specific adaptive immune response (Schuurhuis et al., 2006). DCs may fall into one of two subsets: Myeloid DC (mDC) that express CD11c and present antigens to the naïve CD4 T cells (Steinbrink et al., 2009) or the plasmacytoid DCs (pDC) that express CD123 (Liu, 2001) and have a humble competence in phagocytosis and production of type I interferon (Gilliet et al., 2008). In different types of solid malignancies, the existences of higher percentages of tumor-infiltrating DCs show a mutual relationship with favorable prognosis that highlights their fundamental role in immune surveillance (Yang et al., 2013). Furthermore, the DC can energize the $\mathrm{T}$ cells to overcome the impaired antileukemic Tcell response created by the tumor microenvironment (Schick et al., 2013).

The macrophages (MQ) also perform antigen processing and presentation for $\mathrm{T}$ cells. However, the two macrophages phenotypes play adversative roles. In early stages of tumor development, type 1 macrophages (M1) that actively inhibits cell proliferation and causes tissue damage (Mills, 2012 ) dominates in the tumor microenvironment (Zamarron and Chen, 2011). Later on with advanced malignancies, M2- macrophage phenotype that support tissue repair, remodeling and angiogenesis (Zamarron and Chen, 2011) predominates (Biswas et al., 2001)

NK cells are cytotoxic cells that are highly efficient in killing virally infected and malignant cells (Farag et al., 2003). NK cells are classified into two subsets; CD $16^{\text {tve }}{ }^{\mathrm{CD} 56^{\mathrm{dim}}}$ and the CD16 $6^{\text {-ve/dim }} \mathrm{CD} 56^{\text {bright }}$ (Poli et al., 2009). CD56 $6^{\mathrm{dim}}$ population shows a high cytotoxic ability and constitutes the major percentage of NK cells. CD56 $6^{\text {bright }}$ cells function mainly as immunomodulators via the production of immunoregulatory cytokines such as IL-10, IL-13, TNF $\alpha$, IFN $\gamma$ that can activate DCs and launch adaptive immune response (Camous et al., 2012).

NK cells can identify and eradicate malignant cells without previous antigenic sensitization (Bigley and Simpson, 2015) using their cell surface receptors that includes killer activation receptors (KARs) and killer inhibitory receptors (KIRs). KIRs have a high affinity to HLA class I and function to repress the NK cells preventing them from destruction of normal cells (Bottino et al., 2004). However, absence or abnormal expression of HLA molecules that commonly occurs with malignant transformation set free the NK cells from the inhibitory signals and stimulate their cytotoxicity (Farnault et al., 2012).

NK cells can induce target cell lysis by two central mechanisms; granule exocytosis and liaison of death receptors (Cullen and Martin, 2008). TNF-related apoptosis inducing ligand (TRAIL) expressed by NK cells is qualified for apoptosis induction in TRAIL sensitive cells. Also, NK cells are capable of induction of caspase- dependent apoptosis via Fas/FasL interaction (Smyth et al., 2005).

Siegler et al. (2005) proved that NK cells are key players in immune surveillance in AML. They isolated the NK cells from AML cases before treatment and studied their function in vitro. They demonstrated a high potency in proliferation in response to IL-2 and exhibited proper cytotoxicity towards HLA class I deficient leukemia cells and they were able to reduce AML load. On the same hand, the activating receptor (NKG2D) and the major natural cytotoxicity receptor (NKp46) were normally expressed and they were efficiently releasing interferon gamma. Further studies pointed to the pivotal role of NK cells in AML, Boeck et al. (2017) describe clearly the association of high NK cells percentage with good prognosis. Similarly, the presence of $\geq 5 \%$ circulating NK cells was considered as an independent indicator of ameliorated overall and leukemia-free survival reflecting the clinical importance of NK cells in tumor eradication (Alcasid et al., 2017). However, other researchers demonstrated reduced NK cell cytotoxicity in AML and referred this finding to the different 
strategies of immune evasion made by AML cells (Costello et al., 2002).

\section{Adaptive Immune Response}

Concerning the role of adaptive immunity in tumor immune surveillance, the tumor specific cytotoxic $\mathrm{T}$ lymphocyte plays the starring role (Dunn et al., 2002). TCLs recognize tumor antigens processed and presented by antigen presenting cells (APCs) in context to HLA class I molecules (Ochsenbein et al., 2001). Schneider et al. (2015) proved that $\mathrm{T}$ cells are stimulated against various leukemia associated antigens (LAA) and some of them showed very high immunogenic response for example but not limited to receptors for hyaluronic acid-mediated motility (RHAMM), preferentially expressed antigen of melanoma (PRAME) and Wilm's tumor 1 (WT1) and can induce a considerable suppression of colony forming unites (CFUs) in AML culture.

CTLs share the same mechanisms of tumor cell killing with NK cells; granular exocytosis and induction of apoptosis by FAS/FASL interaction and TRAIL (Barrett and Le-Blanc, 2010). However, tumor -specific $\mathrm{T}$ helper (Th) cells are fundamental for the induction and maintenance of felicitous cytotoxic and memory $\mathrm{T}$ cells response (Lai et al., 2011). The memory $\mathrm{T}$ cells are able to remember previously experienced antigens leading to faster responses and may help with relapse prevention (Schreiber et al., 2011; Dobrzanski, 2013).

Th cells collaborate with CTLs in immune surveillance by grant a license to the DC to permit the cross presentation of LAA to the naive CTLs. Additionally, T helper cells can eliminate tumor cells independently of CTLs as they produce inflammatory cytokines that intensify the phagocytosis and killing ability of the tumor infiltrating macrophages (Haabeth et al., 2011).

In AML, the role of lymphocytes in immune surveillance was highlighted by Le Jeune et al. (2014) who stated that low circulating levels of absolute lymphocyte at diagnosis is a prognostic indicator for shorter overall survival (OS) and leukemia free survival (LFS). Similarly, another study demonstrated that high percentages of BM lymphocytes and $\mathrm{T}$ cells were correlated with achievement of complete remission and prolonged OS (Ismail and Abdulateef, 2017). These data are not conflicting with the studies that demonstrated NK cells as a good prognostic factor in AML as it was assumed that both cells are activated in AML but each function in different phases. Where NK cells are activated at early phase, $\mathrm{T}$ cells are stimulated later on with disease progression (Wang et al., 2015).

\section{AML Evasion from Immune Surveillance}

AML cells together with the microenvironment stimulate many mechanisms that favor their survival and evade riddance by the different immune mechanisms. Generally, these mechanisms are negative regulator for the immune system and they include:

\section{DCs Evasion}

The tumor microenvironment is actively engaged in maturation of DCs. The maturation process could be biased with formation of immunosuppressive DC subsets (Steinman et al., 2003) or convert the conventional DC into regulatory DCs having the potential to stimulate Tregs, secrete transforming growth factor beta (TGF- $\beta$ ) and promoting myeloid-derived suppressor cells. Hence, supporting evolution and expansion of malignant cells (Shurin et al., 2011).

Gangliosides, neuropeptides and nitric oxide (NO) are factors released in the tumor microenvironment that decrease the life span of DCs (Shurin et al., 2012). This decreased longevity will negatively affects the duration and extend of immune response leading to feeble antitumor immune response and tumor elopement from immune recognition (Chen and Wang, 2011). Furthermore, the DCs are often functionally defective with reduced both antigen presentation capabilities and expression of co-stimulatory molecules (Yang et al., 2013). The tumor infiltrating DCs show many functional abnormalities such as inhibited endocytic activity, depressed antigen processing, abnormal migration and decreased IL-2 production (Bennaceur et al., 2009) and moreover, the tumor milieu suppresses the generation and survival of DCs (Onishi et al., 2002).

\section{Evasion of Phagocytosis}

Calreticulin (CRT) is a chaperone protein located in the endoplasmic reticulum (ER). CRT prohibits the abnormally folded proteins from being trans-located to Golgi apparatus. However, stress or apoptosis will cause exportation of CRT to the surface of the cell (Golden et al., 2012). On this new location, CRT will motivate CD91 expressed on the surface of macrophages; hence stimulate phagocytosis (Gardai et al., 2005). The malignant cells can inhibit CRT- stimulated phagocytosis by expression of anti-phagocytic proteins; CD47 (Chao et al., 2010). CD47 interacts with its ligand; signal regulatory protein-A expressed on phagocytes and sending them an inhibitory signal (Subramanian et al., 2007). The human AML blasts demonstrated excessive expression of CD47 which would explain the potentiality of AML blasts to evade phagocytosis (Majeti et al., 2009).

\section{NK Cells Evasion}

Patients with AML have dysfunctional NK cells at diagnosis (Le Dieu et al., 2009) and higher percentages of immature NK cells during first complete remission (CR) (Dauguet et al., 2011). The NK cells obtained from 
all FAB subtypes of AML cases had a skewed receptors phenotype from the normal. They demonstrated low expression of the activating receptor; NKp46 and over expression of inhibitory receptors such as CD158b and NKG2A (Sandoval-Borrego et al., 2016). The repertoire of NK cell receptors in more than $50 \%$ of AML patients revealed the expression of a phenotype that supports tumor evasion from NK cells (Verheyden et al., 2004). Also, the capability of $\mathrm{NK}$ cells to secrete IFN- $\gamma$ is frustrated in AML patients leading to defective immune responses (Coles et al., 2011). This impairment of NK cells cytokine production is linked to early relapse in AML (Lion et al., 2012). TGF- $\beta$ released from the tumor microenvironment reduces NK-cell activation and constringes its cytotoxicity. In acute leukemia, elevated levels of TGF- $\beta$ were consistent with inferior prognosis and were related to diminished NK-cell activity and low expression of the activating $\mathrm{NK}$ cell receptors; NKp30/NCR3 and NKG2D (Baier et al., 2013). Furthermore, TGF- $\beta$ antagonizes the functions induced by IL-15 that include stimulation of NK-cell proliferation and their activation (Baier et al., 2013; Wilson et al., 2011). These functional abnormalities are at least in part induced by the tumor itself as proved by in vitro studies where direct contact between leukemic cells and NK cells induces a loss or decrease in natural cytotoxicity receptors producing a dull phenotype which associates with inferior OS (Fauriat et al., 2007).

\section{Exhaustion of T Helper (Th) Cells}

Persistent antigenic stimulation of T-cell results into a state of hyporesponsiveness termed exhaustion (Wherry and Kurachi, 2015). The myeloblasts express CD86 and inducible T- cell costimulator ligand (ICOSLG) that support Th cell stimulation and proliferation. The persistent stimulation of $\mathrm{T}$ cells leads to their functional fatigue. The exhausted Th cells are identified by increased expression of programmed cell death 1 (PD-1) and the inhibitory receptors such as cytotoxic Tlymphocyte antigen 4 (CTLA-4), lymphocyte activation gene 3 (LAG-3) and mucin domain-containing protein3 (TIM-3). These enervated $\mathrm{T}$ cells are reluctant to proliferate and produce reduced quantities of IL-2, TNF- $\alpha$ and IFN- $\gamma$. Interestingly, T helper cells with the exhausted phenotype were recognized with CD86 (+) and/or ICOS-LG $(+)$ myeloblasts in the BM of AML patients (Ozkazanc et al., 2016).

\section{T Cell Evasion}

The cytotoxicity of T- cells are reduced that may be a direct cause of the over expression of the suppressor molecules such as PD-1(Bos et al., 2012; Shi et al., 2013). Additionally, its ligand; PD-L1 was found to be over expressed in myelobasts (Zhou et al., 2010). The interaction between PD-1 and its ligand would participate in T-cell failure that may be related to persistence of minimal residual disease and development of relapse (Bos et al., 2012; Norde et al., 2011). Furthermore, PD-L1 advocate Tregs by enhancement of their development, maintenance and function (Francisco et al., 2009), which may explain the link between increased Tregs and high PD-1 expression on CTLs and tumor progression (Zhou et al., 2010; Ustun et al., 2011).

Tim-3, a type I membranous glycoprotein, is expressed on CTLs and its ligand; galectin-9 (gal-9) is found on myeloblasts in both animal and human. Tim3/gal-9 pathway possibly contributes with the PD-1/PD$1 \mathrm{~L}$ pathway in regulating $\mathrm{CTL}$ responses. In animal studies, monoclonal antibodies that blocks Tim-3 fusion protein and PD-L1 could restore the antitumor function of exhausted T cells with better AML survival (Zhou et al., 2011). Additionally, hypoxic and acidic conditions created as a result of different metabolic processes in the malignant environment can cause deterioration of the different $\mathrm{T}$ cells functions (Teague and Kline, 2013; Calcinotto et al., 2012).

\section{Regulatory T Cells (Tregs)}

Some studies highlighted the role of Tregs in AML patients. One of these studies demonstrated a significant higher percentage of Tregs than the control and the antileukemic activity of T cells was negatively correlated with Tregs (Schick et al., 2013). Furthermore, another study established a link between the presence of elevated CD25 levels on T helper cells and reduced survival rate (Bołkun et al., 2016). These studies pay the attention towards the Tregs as a factor implicated in impairment of $\mathrm{T}$ cell function and antitumor response either directly or indirectly (Wilke et al., 2011).

Tregs isolated from adult AML cases can synthesis and release IL-35; a novel inhibitory cytokine. IL-35 expands Tregs and inhibits CD4+ve, CD25-ve effector T cells (Teffs) thus promoting AML blasts immune escape. Moreover, IL-35 enhances the proliferation of AML blasts and impairs apoptosis (Tao et al., 2015). Tregs also induce apoptosis in $\mathrm{T}$ helper effector cells through the granzyme B-dependent mechanism in mice (Gondek et al., 2005).

Tregs can suppress Teffs through APC- dependant numerous rotes, including competing them for the same costimulatory receptors (e.g., CD80/86) and prevention of steady interaction between DCs and conventional $\mathrm{T}$ cells (Tadokoro et al., 2006). Tregs inhibit transcription of IL-2 mRNA in the responding $\mathrm{T}$ cells. Supposing that IL-2 is produced normally from the Teff, Tregs expresses a high affinity receptor for IL-2; CD25 that binds to it and decrease the IL-2 available for other $\mathrm{T}$ cells (Thornton et al., 2004; 
Pandiyan et al., 2007). Away from APCs, direct contact between Treg and Teff can cause suppression or programmed cell death of the latter cell (Bopp et al., 2007). In AML, Tregs are highly qualified in hydrolysis of ATP with resultant increase in Treg cAMP levels (Ustun et al., 2011); this cAMP is transferred to Teffs on contact with Tregs. cAMP will decrease IL-2 production with subsequent inhibition of Teff proliferation (Bopp et al., 2007). These findings would oblige us to think that the increased Treg cAMP levels in patients with AML might explain why Tregs in AML patients are more suppressive than Tregs in control patients (Szczepanski et al., 2009).

DCs residing in the BMM in AML have a vigorous chemotactic effect on Tregs, which may be a considerable factor in the accumulation of Tregs (Olsnes et al., 2008). On the other hand, the increased Tregs in AML impair the maturation of normal DCs (Curti et al., 2010). The immature DCs express indolamine (IDO), giving rise to immune inhibition both by depleting tryptophan, which interrupt cell cycle progression in $\mathrm{T}$ cells and inhibits their proliferation. Increasing kynurenines; tryptophan metabolites which is toxic to $\mathrm{T}$ cells, will promote $\mathrm{T}$-cell apoptosis (Mellor and Munn, 2004). Both IDO activity in the serum of AML patient (Corm et al., 2009) and its expression in myeloblasts (Curti et al., 2007) were found to be increased. Interestingly, AML patients with IDO +ve myeloblasts were shown to have extra Tregs compared with IDO -ve patients and in vitro studies showed that IDO + ve myeloblasts in humans and mice can transform CD4+ve, CD25-ve (Th) cells into CD4+ve, CD25+ve (Tregs) cells (Curti et al., 2009). Regarding the effect of IDO on AML patient's survival, it was reported that high IDO mRNA expression in leukemic blasts (Chamuleau et al., 2008) and high IDO activity(Corm et al., 2009) were associated with poor survival.

CD200 is over expressed in leukemic blasts in $43 \%$ of AML patients (Tonks et al., 2007). CD200 interact with its ligand on T- cells, B- cells and DC results in their suppression (Gorczynski et al., 2005). Interestingly, the expression of CD200 on the AML blasts was correlated with a more frequent Tregs in the BM (Coles et al., 2010) and it directly inhibits the cytotoxic activity of NK cells (Coles et al., 2011) (Fig. 1).

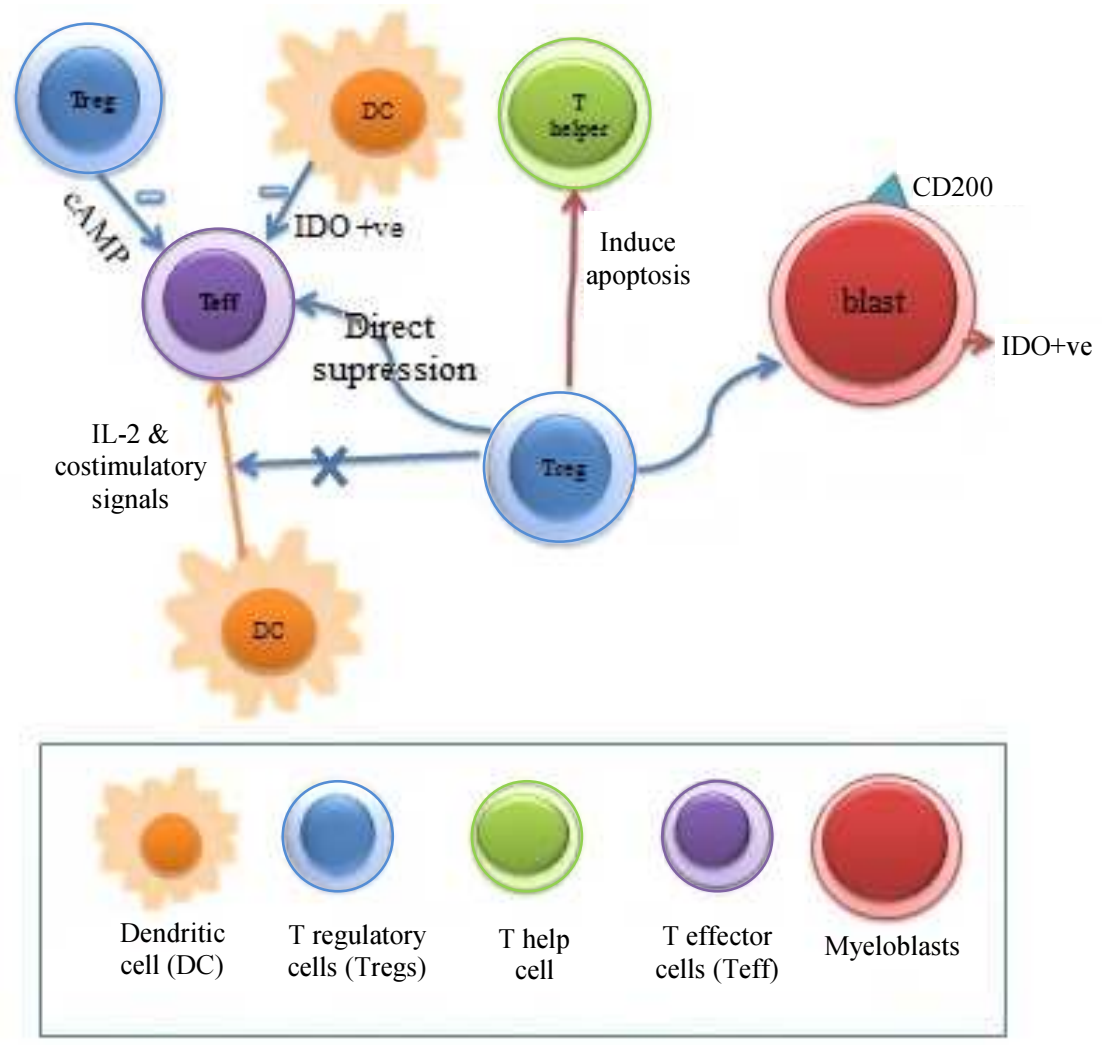

Fig. 1: Interaction between T regulatory cells and other immune cells in acute myeloid leukemia. Tregs produces IL-35 that inhibits $\mathrm{T}$ helper cells and directly reduces the apoptosis of AML blasts and promotes their proliferation. Tregs directly inhibit Teff cells either directly or via inhibition of DC. Tregs inhibit Teff by cAMP pathway. both DC and blast cells express Indoleamine 2, 3-Dioxygenase (IDO), which causes immune suppression 


\section{T Helper 17}

In AML patients, either newly diagnosed or not in remission, Th17 (CD3+ve, CD4+ve, IL-17+ve) was considerably increased in relation to the control (Abousamra et al., 2013; Musuraca et al., 2015; Yu et al., 2014) and reduced significantly after remission completion (Abousamra et al., 2013). Additionally, the circulating IL-17 in acute leukemia showed remarkable elevated levels compared to the control and decreased to a notable level after 6 months of chemotherapy (Musuraca et al., 2015; Xiang et al., 2016). Also, Th17 release IL-10 with its known immunosuppressive properties (Musuraca et al., 2015). An inverse relationship was found between depletion of Th17 and restoration of IFN- $\gamma$ production from T cells in AML. These findings denote that altered Th17 cells actively promote AML escape by induction of an immunosuppressive state (Musuraca et al., 2015).

\section{Myeloid Derived Suppressor Cells (MDSCs)}

MDSCs have a characteristic phenotype being CD33+ve, CD11b+ve, HLA-DR low/-ve. They are closely related to neutrophils and monocytes. MDSCs are not present under normal conditions (Gabrilovich, 2017). Cytokines and growth factors derived from the malignant cells can induce shift of hematopoiesis towards the development and proliferation of MDSCs (De Sanctis et al., 2016). They can inhibit T cells, NK cells and APCs and frustrate the advantageous immune reactions (Meirow et al., 2015) hence promoting tumor growth (Malek et al., 2016).

MDSCs can hinder the proliferation of tumor specific $T$ cells and inhibit their cytotolytic potential (Chesney et al., 2017) by many mechanisms including; damaging lack of amino acids essential for $\mathrm{T}$ cells, inducement of oxidative stress, interference with $\mathrm{T}$ cell trafficking and hamper their viability (Motallebnezhad et al., 2016) as well as by promoting expansion of Tregs. Thereby, dampening the host immune responses against the tumor (Chesney et al., 2017) and enhance shifting of the immune system towards tumor tolerance (Parker et al., 2015). In addition, tumor-infiltrating MDSCs can express IDO in animal models (Jia et al., 2010) that play a critical role in Tregs induction in the tumor microenvironment (Ustun et al., 2011). Sun et al. (2015) reported that, in the BM of newly diagnosed adult AML, MDSCs were found to be increased and significantly reduced after complete remission. Also the achievement of remission was inferior in the group that had higher MDSCs count. High count of MDSCs was correlated with WT-1 protein and extramedullary spread denoting a possible role of these cells in AML prognosis.

\section{Immunosenescence}

Immunosenescence involves age-associated restructuring changes of innate and adaptive immune functions (Baeza et al., 2011). The aging process that affect the innate immunity results in reduced ability to initiate adaptive immunity, together with enhanced inflammatory reactions (Panda et al., 2009; Shaw et al., 2010). Consequently, immunosenescence would affect the immune surveillance properties of the immune system and add more burden together with the evasion mechanisms created by AML blats that collectively promote the development of the disease (Fig. 2). These changes will be highlighted in the following section.

\section{Aging of the Innate System}

The drastic changes that occurs in the innate system due to senility mainly results in the deterioration of the different functions of NK and DC cells as a consequence, contribute to the increase prevalence of malignancy as a result of diminished tumoricidal effect of NK cells and impaired activation of $\mathrm{T}$ cells (Henry et al., 2011). In addition, the aging process that affect innate immunity result in enhanced inflammatory reactions; inflammaging that usually precedes the development of malignancy (Panda et al., 2010; Shaw et al., 2010).

The DC and MQ phenotype in aging shows low levels of MHC- class II expression (Strohacker et al., 2010; Garbe et al., 2012) that will be associated with decreased antigen presentation to $\mathrm{T}$ cells (Plowden et al., 2004). The competence of these professional APCs to introduce costimulatory signals to the $\mathrm{T}$ cells is diminished as a result of reduced expression of CD80 (Strohacker et al., 2010). Prostaglandine E2 synthesis and release by MQ is enhanced that can also repress $T$ cell functions (Solana et al., 2012).

Signaling via toll like receptors (TLRs) is absolutely necessary for DCs activation. In old age, there is decreased TLR signaling that may be related to down regulation (Rosenstiel et al., 2008; Montoya-Or Tiz, 2013) or unresponsiveness (Gomez et al., 2005; Shaw et al., 2013) this will ends in aberrant secondary immune cell activation (Rosenstiel et al., 2008; Montoya-Or Tiz, 2013). Reduced TLR signaling will results in defective upregulation of TLR- dependant expression of CD80 and CD86 this in turn will impair the function of DC and MQ as APCs due to their failure to supply $\mathrm{T}$ cells with the costimulatory signal (Van Duin et al., 2007).

With advanced aging, the movement of DCs towards the concentration gradient of chemokines 
(MIP-3 $\beta$, SDF-1) is reduced, which might negatively affects their migration to lymph nodes and induction of immune responses (Agrawal et al., 2007). Also, their potentiality to form cytokines like IL- 15 , INF- $\alpha$ and TNF- $\alpha$ is reduced (Stout-Delgado et al., 2008). TNF- $\alpha$ is a pivotal cytokine in CTLs activation via DC hence, its reduction will impedes stimulation of $\mathrm{T}$ cells (Liu and Zheng, 2012).

Defective NK cells cytotoxicity is observed during aging that may be related to many factors (i) Defective signal transduction due to reduced release of IP3. (ii) Defective granule exocytosis (Mariani et al., 1998). (iii) Diminished capacity to release perforin that consequently results in reduced killing effect on target cells (Hazeldine et al., 2012).(iv) Deficiency of the natural cytotoxicity receptors e.g. NKp46 (Hazeldine et al., 2012) and NKp30 (Almeida-Oliveira et al., 2011). However, the $\operatorname{CD} 56^{\mathrm{dim}} \mathrm{NK}$ population is increased in number as a trial to compensate this defective cytotoxicity (Di Lorenzo et al., 1999) but this expansion occurs on the expense of the CD56 ${ }^{\text {bright }}$ population (Chidrawar et al., 2006) that mainly functions as immunoregulator and an amble source of IFN- $\gamma$ which is reduced in the elderly by $75 \%$ in relation to the younger samples (Chidrawar et al., 2006; Solana et al., 2012).

\section{Aging of the Adaptive System}

The primary process in age associated immune frailty is the decrease in the thymic output that occurs as a result of thymic involution (Hakim and Gress, 2007). Measurement of TCR excision circle that denotes recent emergence from the thymus gland (Sempowski et al., 2001), revealed that the output of the naive $\mathrm{T}$-cell in old age decreases up to $80 \%$ (Arnold et al., 2011), which affects both T helper and cytotoxic but the cytotoxic cells are more affected. Consequently, $\mathrm{T}$ cell diversity will be reduced, which put a fixed $\mathrm{T}$-cell immune repertoire in front of rapidly growing tumor cells and tumor permissive microenvironment (Czesnikiewicz-Guzik et al., 2008). Thus initiating an unjustified battle that ends in cancer propagation. With respect to the response of the naïve $\mathrm{T}$ cells to IL-2 stimulation, the naïve cells show reduced proliferation and differentiation in senility compared to the young age (Zediak et al., 2007).

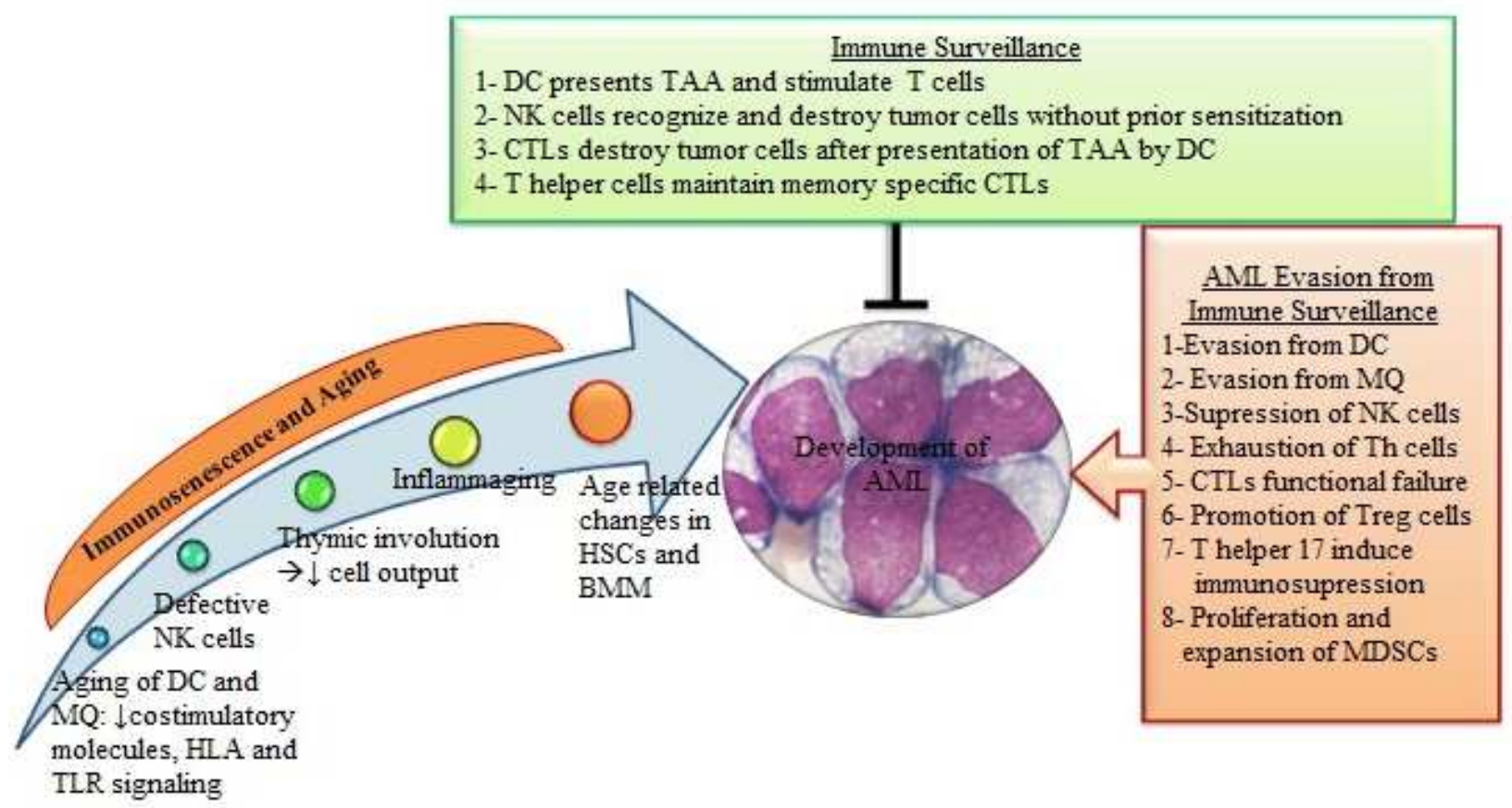

Fig. 2: Outline of the immune mechanisms that affect the development of acute myeloid leukemia in old age. Immune surveillance can eradicate the tumor cells or maintain an equilibrium state, however this function is opposed by the evasion mechanisms created by AML blasts and additionally became weaker with immunosenescence and age related changes in BMM and HSCs. AML: Acute myeloid leukemia, BMM: Bone marrow microenvironment, CTL: Cytotoxic T lymphocytes, DC: Dendritic cells, HLA: human leukocyte antigen, HSCs: Haematopoietic stem cells, MDSC: Myeloid derived suppressor cells, MQ: Macrophages, NK: Natural killer cells, TAA: Tumor associated antigens, TLR: Toll like receptors 
The costimulatory molecules on CTLs shows reverted distribution in caducity were CD28 is decreases, CTLA-4 is increased which binds to CD28 ligands (CD80 and 86) on APCs and inhibits CTLs (Parish et al., 2010a). Additionally, the CD28 negative T cells can causes non reactivity of $\mathrm{T}$ helper cells (Effros, 2010).

The process of cancer immunediting indicates that tumor cells continuously produce novel antigens due to their genetic instability. Thereafter, these novel antigens are presented by APCs to the CTLs and assigned for immune destruction. However, in old age the CTLs have a limited diversity and will lose their eligibility to interact with the novel TAA (Beatty et al., 2009). In aged AML patients, senescent $\mathrm{T}$ cells (CD28-ve, CD57+ve and short telomerase) have been isolated. These cells have a weaken ability to perform most of the effector functions such as proliferation, cytokines release, or degranulation despite their ability to recognize different epitopes derived from TAA (Beatty et al., 2009).

Aged naive Th cells live longer as a consequence of reduced expression of the proapoptotic molecule; Bim (Tsukamoto et al., 2010) but proliferate less mostly due to shorter telomerase (Kilpatrick et al., 2008), produce reduced levels of IL-2 when stimulated and are not influential in assisting B cell (Eaton et al., 2004). This longer life span keep sufficient number of the cells to compensate for the reduced production but the side effect of this longevity is the development of $\mathrm{T}$ helper functional impairment (Tsukamoto et al., 2009).

The effector $\mathrm{T}$ cell response is counting on the rapid expansion and subsequent cell survival to form longlived memory T cells. Proliferation is associated with considerable genomic stress and the activation of DNA damage response pathways, which are increasingly compromised with immune aging (Cavanagh et al., 2012). Best known is telomeric erosion due to a decline in repair mechanisms, in particular the expression of telomerase (Hodes et al., 2002). Age-associated telomeric erosion is seen in naïve T cells and extra in the effector CTLs, in which telomerase appears to limit clonal expansion (Parish et al., 2010b).

Finally differentiated CTLs overexpress miR-24, which down-regulates the expression of histone variant; H2AX (Brunner et al., 2012). As a consequence, DNA damage responses to genotoxic stress are impaired in these cells with reduced serine phosphorylation of ataxia telangiectasia mutated (ATM) and p53. This will be translated functionally into increased apoptosis susceptibility and a decreased replicative capacity, which dampens $\mathrm{T}$ cell responses (Brunner et al., 2012). A variation in the signal transduction pathways NF- $\kappa \beta$ and MAPK was noted (Deruy et al., 2014; Jing and Lee, 2014) together with reduced miR-181a. This would be associated with lose control upon lymphocyte activation with poor response (Mariani et al., 1998).

Senility is associated with progressive reduction in memory formation as proved from vaccination studies (Bouree, 2003). This would impair one of the main advantages of the adaptive immune system; formation of memory. The hazard of losing efficient memory especially to the newly emerging tumor antigens is deterioration of the immune system ability to hinder disease recurrence in elderly patients (Foster et al., 2011).

One of the features of the immunosenescence is the increase in Tregs that enforces the tendency towards immune suppression in old age (Cusi et al., 2010). In AML, Tregs are also increased (Schick et al., 2013) representing one of the immune evasion mechanisms (Watanabe et al., 2010). This double increase in Tregs would critically impair immune response in old AML patients.

\section{Inflammaging}

It is low- grade chronic sterile inflammation that occurs in old age (Franceschi and Campisi, 2014) probably occurs as a result of persistent subjection to antigens together with a substandard immune functions mostly characterized by aged MQ and T cells in addition to increased proinflammatory cytokines (Campos et al., 2014).

Cellular senescence is accompanied by accumulation of danger-associated molecular patterns (DAMPs) (Rubartelli and Lotze, 2007) that enhance innate immunity (Feldman et al., 2015) via stimulation of three different groups of receptors; TLR (Piccinini and Midwood, 2010), NOD-Like receptors (NLRs) (Strowig et al., 2012) and cytosolic DNA sensor (Keating et al., 2011). DAMPs will stimulate TLR leading to stimulation of the pro-inflammatory transcription factors; NF- $\kappa \beta$ with subsequent elevation in an amble of inflammatory cytokines such as TNF- $\alpha$, IL$1 \beta$ and IL-12 and enhancement of type I interferondependant immune response (Piccinini and Midwood, 2010). DAMPs warn the NLRs that cause increase in IL$1 \beta$ and IL-18 via inflammasome assembly that promote maturation of the inflammatory cytokines (Strowig et al., 2012). Also, inflammasome signaling and type I IFN response can be stimulated by dsDNA (Keating et al., 2011). Enhanced activation of the coagulation system and inadequate regulation of the complement system are extra sources for inflammaging (Franceschi and Campisi, 2014).

Another crucial component of the inflammatory responses is the aging of the immune system itself, which in favor of supporting the proinflamatory status by the following mechanisms (i) The considerable changes of monocyte subsets with age with increase in non-classical 
monocytes (CD14 ${ }^{+\mathrm{ve}}, \mathrm{CD} 16^{+\mathrm{ve}}$ ) (Iida et al., 2011); a major source of proinflammatory cytokines e.g. IL6, IL1 $\beta$ (Sadeghi et al., 1999). (ii) Release of proinflammatory cytokines comprising IFN- $\gamma$ and TNF- $\alpha$, by $\mathrm{CD}^{+\mathrm{ve}} \mathrm{T}$ cells. The increase in TNF- $\alpha$ level has a mutual relationship with dismal prognosis in hematological malignancies (Malaguarnera et al., 2010). (iii) Augmentation in the number Th17 cells that release IL-17 with its well known proinflammatory properties (Ouyang et al., 2011) and it is demonstrated to be increased in AML (Abousamra et al., 2013).

Senile hematopoietic stem cells display an enhancement of the inflammatory pathways as well (Franceschi and Campisi, 2014). It was proposed that the potentiality of hematopoietic cell in humans is conserved during the whole life and the main changes are due to reconstruction of the hematopoietic cytokine network with advanced age (Bagnara et al., 2000). Intriguingly, it was noticed that age dependant modulation of the stem cell pool are responsible for deviation towards myeloid series (Woolthuis et al., 2011) which in turn leads to increased macrophages; the major player in inflammaging (Franceschi et al., 2007). The inflammatory cytokines produced by macrophages, e.g., TNF- $\alpha$, boosts proliferation of malignantly transformed cells by induction of death of the normal cells. Hence, giving a space for proliferation of cancer cells (Karin et al., 2006). Furthermore, chronic inflammation promotes recruitment of MDSCs with their mentioned inhibitory properties (Meyer et al., 2011). Overall, these observations supports the concept that the age-related shift of the hematopoietic microenvironment toward a proinflammatory phenotype can contribute to hematopoietic malignancy.

\section{Clinical Significance and Conclusion}

Away from the immune system, senility had a negative effect on many protective mechanisms against malignancy. These negative effects includes defective DNA repair, telomere shortening, chromosomal instability, modulation of intercellular communication and scarcity in apoptosis- controlling genes (Campisi, 2013). Then again, malignant cells are distinguished by sustained proliferation, uncontrolled expansion, resistance to apoptosis and the capability to evade immune surveillance (Fouad and Aanei, 2017). These criteria of aging and malignancy appear to be contradictory but it emphasizes the mission of the microenvironment which directs both cellular and molecular events in the surrounding tissue. Tumor microenvironment is dictated and promoted by the malignant cells and in turn, it actively promotes tumors. In AML, the immune cells interact with the tumor cells and all other components within this microenvironment. This interaction generates a network of immunosuppressive mechanisms, while activation of the normal immune protective responses are impeded to evade the immune surveillance (Whiteside, 2010). However, the immune cells responsible for surveillance together with the tumor microenvironment have already been altered with aging leading to a state of immune frailty that adds more to the evasion mechanisms.

A clear view of the aging changes and the evasion mechanisms mediated by AML malignant cells demonstrate that the AML cells can perform several mechanisms to evade from the killing potential of NK and CTLs and potentiate the immune inhibitory cells such as Tregs and MDSCs. With aging the NK cytotoxic ability per cell is diminished, the potentiality of the DC to perform antigen presentation is hampered and $\mathrm{T}$ cell diversity decreases due to thymic involution with defective proliferation. Those factors together with the previously mentioned evasion mechanisms would fasten the transition from the equilibrium to the escape phase of tumor development. Moreover, inflammaging creates a hazardous microenvironment that promotes oncogenic events. In this setting of age-impaired immunity, together with the other age related changes occur in HSC and BMM would initiate and promote cancer cells resulting in increased frequency of hematological malignancies that is truly perceived with advanced age.

AML in elder age group has a dismal outcome with 5 years OS less than $5 \%$, as compared to $40 \%$ in the young (Alibhai et al., 2001). This poor outcome is related to both patient and disease-related factors. Ageing often coexists with enfeeblement and comorbidities that negatively affect their tolerance to intensive treatment modalities (Mohammadi et al., 2015). AML in the elderly has distinct biological criteria different from the young age group with higher incidence of multiple chromosomal abnormalities, mutations in genes coding for epigenetic regulators, kinases and cell cycle regulators and transcription factors (Almeida and Ramos, 2016). Additionally, immunosenescence adds more to the different biological properties of AML in elderly.

Understanding the role of immunosenescence and evasion mechanisms in the development and progress of AML will help with proper choice of therapy. Naturally, the immune cells are anatomically and functionally close to the myeloid cells in the BM. This interaction provides a unique area for development of immunotherapeutic strategies that targets the blasts and enforces immune surveillance. Monoclonal antibodies were used to target specific AML antigens with effective results and minimal toxicity. In recent years, a number of these antigens emerged such as CD33, CD123, CD96, CD47 and CD25 (Majeti, 2011). Despite that most efforts have focused on CD33, CD47 have revealed potent efficacy against AML-LSC in 
xenotransplantation models that would both target the blast cells and inhibit one of immune evasion strategies. Hopefully, these antibodies will at the latest be advantageous in the treatment of AML.

Recording the negative influence of aging on NK cells with evasion mechanisms would make the NK cells a proper target for immunotherapy in old AML patients that is emphasized to be safe and effective (Rubnitz et al., 2010). The usage of anti-KIR antibodies that block KIRs would increases the activity of NK cells; a requirement for effective antileukemic response (Vey et al., 2012). Trial using IL-2 diphtheria toxin fusion protein results in depletion of Tregs proliferation, hence overcome their inhibitory effect on NK cells (Bachanova et al., 2014).

Targeting AML blasts with adoptive $\mathrm{T}$ cells is an interesting line of therapy but its benefit may be limited by the immune modalities made by the AML itself to evade the $\mathrm{T}$ cells that necessitates combined monoclonal antibody therapy such as PD-1 blockade, blockade of CTLA-4, administration of adenosine antagonists and IDO inhibitors may create a tumor environment that enhances the effectiveness of cellular immunotherapy (Ohta and Sitkovsky, 2014). However older patients may get benefit first from restoration of the thymic function by the use of cytokines known to improve thymopoiesis such as IL-7and growth hormone (Taube et al., 2012) because evidence advocate that aged precursors can complete their development normally if they are located in a young thymic environment (Garbe et al., 2012). To overcome replicative senescence in $\mathrm{T}$ cells, treatment modalities that support telomerase activity may be tried (Effros, 2010). Another prospective strategy to reduce the prevalence of cancer in old age is to impede the proinflammatory environment by exploiting currently obtainable medications used in chronic inflammatory diseases (Korkaya et al., 2011; Jones et al., 2011).

Peptide vaccines using leukemia associated antigens (e.g., WT1, proteinase 3 and RHAMM) to stimulate CTLs was tried in AML cases to stimulate antileukemic responses and thereby control minimal residual disease (Grosso et al., 2015). However, this would be of a limited value because of the finite response to vaccines noticed in old age with less effective development of immunological memory.

As research in the field progresses, novel therapeutic modalities to actively support the immune function, essentially in the senile age group, will occupy a prominent place in the armamentarium against this difficult disease in that critical age.

\section{Conflict of Interest}

The author declares that there is no conflict of interest.

\section{References}

Abousamra, N.K., M. Salah El-Din and R. Helal, 2013. Prognostic value of Th17 cells in acute leukemia. Med. Oncol., 30: 732-732.

DOI: $10.1007 / \mathrm{s} 12032-013-0732-3$.

Agrawal, A., S. Agrawal, J.N. Cao, H. Su and K. Osann et al., 2007. Altered innate immune functioning of dendritic cells in elderly humans: A role of phosphoinositide 3-kinase-signaling pathway. J. Immunol., 178: 6912-6922.

DOI: $10.4049 /$ jimmunol.178.11.6912

Alcasid, M., L. Ma, J.R. Gotlib, D.A. Arber and R.S. Ohgami, 2017. The clinicopathologic significance of lymphocyte subsets in acute myeloid leukemia. Int. J. Laboratory Hematol., 39: 129-136. DOI: $10.1111 /$ ijlh. 12594

Alibhai, S.M., M. Leach, M.D Minden and J. Brandwein, 2001. Outcomes and quality of care in acute myeloid leukemia over 40 years. Cancer, 115: 2903-2911. DOI: 10.1002/cncr.24373

Almeida, A.M. and F. Ramos, 2016. Acute myeloid leukemia in the older adults. Leukemia Res. Rep., 6: 1-7. DOI: $10.1016 /$ j.Irr.2016.06.001

Almeida-Oliveira, A., M. Smith-Carvalho, L.C. Porto, J. Cardoso-Oliveira and S. Ribeiro Ados et al., 2011. Age-related changes in natural killer cell receptors from childhood through old age. Human Immunol., 72: 319-29. DOI: 10.1016/j.humimm.2011.01.009

Arnold, C.R., J. Wolf, S. Brunner, D. HerndlerBrandstetter and B. Grubeck-Loebenstein, 2011. Gain and loss of $\mathrm{T}$ cell subsets in old age-agerelated reshaping of the $\mathrm{T}$ cell repertoire. J. Clin. Immunol., 31: 137-146. DOI: $10.1007 / \mathrm{s} 10875-010-9499-x$

Ashley, P., L. Barreyro and U. Steidl, 2013. Concise review: Preleukemic stem cells: Molecular biology and clinical implications of the precursors to leukemia stem cells. Stem Cells Translat. Med., 2: 143-150. DOI: $10.5966 /$ sctm.2012-0109

Bachanova, V., S. Cooley, T.E. De-For, M.R. Verneris and B. Zhang et al., 2014. Clearance of acute myeloid leukemia by haploidentical natural killer cells is improved using IL-2 diphtheria toxin fusion protein. Blood, 123: 3855-3863.

DOI: 10.1182/blood-2013-10-532531

Baeza, I., N.M. De-Castro, L. Arr Anz, E.S.J. Fdeztresguerr and M. De La- Fuente, 2011. Ovariectomy causes immunosenescence and oxiinflamm-ageing in peritoneal leukocytes of aged female mice similar to that in aged males. Biogerontology, 12: 227-238.

DOI: $10.1007 / \mathrm{s} 10522-010-9317-0$ 
Bagnara, G.P., L. Bonsi, P. Strippoli, F. Bonifazi and R. Tonelli et al., 2000. Hemopoiesis in healthy old people and centenarians: Well-maintained responsiveness of CD34 cells to hemopoietic growth factors and remodeling of cytokine network. J. Gerontol. A, 55: B61-66.

Baier, C., A. Fino, C. Sanchez, L. Farnault and P. Rihet et al., 2013. Natural killer cells modulation in hematological malignancies. Frontiers Immunol., 4: 4-459. DOI: $10.3389 /$ fimmu.2013.00459

Barrett, A.J. and K. Le Blanc, 2010. Immunotherapy prospects for acute myeloid leukemia. Clin. Exp. Immunol., 161: 223-32.

Beatty, G.L., J.S. Smith, R. Reshef, K.P. Patel and T.A. Colligon et al., 2009. Functional unresponsiveness and replicative senescence of myeloid leukemia antigenspecific CD8+ $\mathrm{T}$ cells after allogeneic stem cell transplantation. Clin. Cancer Res., 15: 4944-4953. DOI: 10.1158/1078-0432.CCR-08-3332

Bennaceur, K., J.A. Chapman, J.L. Touraine and J. Portoukalian, 2009. Immunosuppressive networks in the tumour environment and their effect in dendritic cells. Biochim. Biophys. Acta, 1795: 16-24.

DOI: $10.1016 /$ j.bbcan.2008.07.001

Bigley, A.B. and R.J. Simpson, 2015. NK cells and exercise: Implications for cancer immunotherapy and survivorship. Discovery Med., 19: 433-445. PMID: 26175401

Biswas, S.K., A. Sica and C.E. Lewis, 2001. Plasticity of macrophage function during tumor progression: Regulation by distinct molecular mechanisms. J. Immunol., 180: 2011-2017. DOI: $10.4049 /$ jimmunol.180.4.2011

Boeck, C.L., D.C. Amberger, F. Doraneh-Gard, W. Sutanto and T. Guenther et al., 2017. Significance of frequencies, compositions and/or antileukemic activity of (DC-stimulated) invariant NKT, NK and CIK cells on the outcome of patients with AML, ALL and CLL. J. Immunotherapy, 40: 224248. DOI: $10.1097 /$ CJI.0000000000000171

Bołkun, Ł., M. Rusak, A. Eljaszewicz, L. Pilz and U. Radzikowska et al., 2016. Enhanced pretreatment CD25 expression on peripheral blood CD4+ T cell predicts shortened survival in acute myeloid leukemia patients receiving induction chemotherapy. Pharmacol. Rep., 68: 12-9.

DOI: $10.1016 /$ j.pharep.2015.05.025

Bonafe, M., G. Storci and C. Franceschi, 2011. Inflamm-aging of the stem cell niche: Breast cancer as a paradigmatic example: Breakdown of the multi-shell cytokine network fuels cancer in aged people. Bioassays, 34: 40-49.

DOI: $10.1002 /$ bies.201100104
Bopp, T., C. Becker, M. Klein, S. Klein-Hessling and A. Palmetshofer et al., 2007. Cyclic adenosine monophosphate is a key component of regulatory $\mathrm{T}$ cell-mediated suppression. J. Exp. Med., 204: 1303-1310. DOI: 10.1084/jem.20062129

Bos, R., K.L. Marquardt, J. Cheung and L.A. Sherman, 2012. Functional differences between low- and high-affinity $\mathrm{CD} 8+\mathrm{T}$ cells in the tumor environment. Oncoimmunology, 6: 1239-1247. DOI: 10.4161 /onci.21285

Bottino, C., L. Moretta, D. Pende, M. Vitale and A. Moretta, 2004. Learning how to discriminate between friends and enemies, a lesson from natural killer cells. Mol. Immunol., 41: 569-575. DOI: 10.1016/j.molimm.2004.04.004

Bouree, P., 2003. Immunity and immunization in elderly. Pathol. Biol., 51: 581-585. DOI: $10.1016 /$ j.patbio.2003.09.004

Brunner, S., D. Herndler-Brandstetter, C.R. Arnold, G.J. Wiegers and A. Villunger et al., 2012. Upregulation of miR-24 is associated with a decreased DNA damage response upon etoposide treatment in highly differentiated $\mathrm{CD} 8+\mathrm{T}$ cells sensitizing them to apoptotic cell death. Aging Cell, 11: 579-587. DOI: $10.1111 /$ j.1474-9726.2012.00819.x

Calcinotto, A., P. Filipazzi, M. Grioni, M. Iero and A. De-Milito et al., 2012. Modulation of microenvironment acidity reverses anergy in human and murine tumor-infiltrating $\mathrm{T}$ lymphocytes. Cancer Res., 72: 2746-2756.

DOI: 10.1158/0008-5472.CAN-11-1272

Camacho, V., V. Mc Clearn, S. Patel and R.S. Welner, 2017. Regulation of normal and leukemic stem cells through cytokine signaling and the microenvironment. Int. J. Hematol., 105: 566-77. DOI: $10.1007 / \mathrm{s} 12185-017-2184-6$

Camous, X., A. Pera, R. Solana and A. Larbi, 2012. NK cells in healthy aging and age-associated diseases. J. Biomed. Biotechnol., 2012: 195956-195956. DOI: $10.1155 / 2012 / 195956$

Campisi, J., 2013. Aging, cellular senescence and cancer. Annual Rev. Physiol., 75: 685-705. DOI: 10.1146/annurev-physiol-030212-183653

Campos, C., A. Pera, I. Lo Pez-Fernandez, C. Alo Nso and R. Tarazona et al., 2014. Proinflammatory status influences NK cells subsets in the elderly. Immunol. Lett., 162: 298-302. DOI: $10.1016 /$ j.imlet.2014.06.015

Carlesso, N. and A.A. Cardoso, 2010. Stem cell regulatory niches and their role in normal and malignant hematopoiesis. Curr. Opin. Hematol., 17: 281-286.

DOI: 10.1097/MOH.0b013e32833a25d8 
Cavanagh, M.M., C.M. Weyand and J.J. Goronzy, 2012. Chronic inflammation and aging: DNA damage tips the balance. Curr. Opin. Immunol., 24: 488-493. DOI: $10.1016 /$ j.coi.2012.04.003

Chamuleau, M.E., A.A. van de Loosdrecht, C.J. Hess, J.J. Janssen and A. Zevenbergen et al., 2008. High INDO (indoleamine 2,3-dioxygenase) mRNA level in blasts of acute myeloid leukemic patients predicts poor clinical outcome. Haematologica, 93: 1894-1898. DOI: 10.3324/haematol.13112

Chao, M.P., S. Jaiswal, R. Weissman-Tsukamoto, A.A. Alizadeh, amd A.J. Gentles et al., 2010. Calreticulin is the dominant pro-phagocytic signal on multiple human cancers and is counterbalanced by CD47. Sci. Translat. Med. J., 2: 63-94.

DOI: 10.1126/scitranslmed.3001375

Chen, M. and J. Wang, 2011. Regulation of immune responses by spontaneous and $\mathrm{T}$ cell-mediated dendritic cell death. J. Clin. Cellular Immunol., 11: 005-005.

Chesney, J.A., R.A. Mitchell and K. Yaddanapudi, 2017. Myeloid-derived suppressor cells-a new therapeutic target to overcome resistance to cancer immunotherapy. J. Leukocyte Biol., 102: 727-740. DOI: $10.1189 / \mathrm{jlb} .5 \mathrm{VMR} 1116-458 \mathrm{RRR}$

Chidrawar, S.M., N. Khan, Y.L. Chan, L. Nayak and P.A. Moss, 2006. Ageing is associated with a decline in peripheral blood CD56 $6^{\text {bight }} \mathrm{NK}$ cells. Immunity Age., 3: 10-10.

DOI: $10.1186 / 1742-4933-3-10$

Chiorazzi, N., K. Hatzi and E. Albesiano, 2005. B-Cell chronic lymphocytic leukemia, a clonal disease of B lymphocytes with receptors that vary in specificity for (Auto) antigens. Annals New York Acad. Sci., 1062: 1-12. DOI: 10.1196/annals. 1358.002

Coles, S.J., E.C. Wang, S. Man, R.K. Hills and A.K. Burnett et al., 2011. CD200 expression suppresses natural killer cell function and directly inhibits patient anti-tumor response in acute myeloid leukemia. Leukemia, 25: 792-799.

DOI: $10.1038 /$ leu.2011.1

Coles, S.J., S. Man, R. Hills, E.C.Y. Wang and A. Burnett et al., 2010. Over-expression of CD200 in acute myeloid leukemia mediates the expansion of regulatory T-lymphocytes and directly inhibits natural killer cell tumor immunity. Blood, 116: 491-491.

Cooley, S., D.J. Weisdorf, L.A. Guethlein, S.1. Cooley and J.P. Klein et al., 010. Donor selection for natural killer cell receptor genes leads to superior survival after unrelated transplantation for acute myelogenous leukemia. Blood, 116: 2411-2419. DOI: 10.1182/blood-2010-05-283051
Corm, S., C. Berthon, M. Imbenotte, V. Biggio and M. Lhermitte et al., 2009. Indoleamine 2,3-dioxygenase activity of acute myeloid leukemia cells can be measured from patients' sera by HPLC and is inducible by IFN- $\gamma$. Leukemia Res., 33: 490-494. DOI: $10.1016 /$ j.leukres.2008.06.014

Costello, R.T., S. Sivori, E. Marcenaro, M. LafagePochitaloff and M.J. Mozziconacci et al., 2002. Defective expression and function of natural killer cell-triggering receptors in patients with acute myeloid leukemia. Blood, 99: 3661-3667.

DOI: 10.1182/blood.V99.10.3661

Cullen, S.P. and S.J. Martin, 2008. Mechanisms of granule-dependent killing. Cell Death Different.., 15: 251-62. DOI: 10.1038/sj.cdd.4402244

Curti, A., S. Pandolfi, B. Valzasina, M. Aluigi and A. Isidori et al., 2007. Modulation of tryptophan catabolism by human leukemic cells results in the conversion of CD25- into CD25+ T regulatory cells. Blood, 109: 2871-2877.

DOI: 10.1182/blood-2006-07-036863

Curti, A., S. Trabanelli, C. Onofri, M. Aluigi, V. Salvestrini, D. Ocadlikova, et al. 2010. Indoleamine 2,3-dioxygenase-expressing leukemic dendritic cells impair a leukemia-specific immune response by inducing potent $\mathrm{T}$ regulatory cells. Haematologica, 95: 2022-2030.

DOI: $10.3324 /$ haematol.2010.025924

Curti, A., S. Trabanelli, V. Salvestrini, M. Baccarani and R.M. Lemoli, 2009. The role of indoleamine 2,3dioxygenase in the induction of immune tolerance: Focus on hematology. Blood, 113: 2394-2401. DOI: 10.1182/blood-2008-07-144485

Cusi, M.G., B. Martorelli, G. Di Genova, C. Terrosi and G. Campoccia et al., 2010. Age related changes in T cell mediated immune response and effector memory to Respiratory Syncytial Virus (RSV) in healthy subjects. Immunity Ageing, 7: 14-14.

DOI: $10.1186 / 1742-4933-7-14$

Czesnikiewicz-Guzik, M., W.W. Lee, D. Cui, Y. Hiruma and D.L. Lamar et al., 2008. T cell subset-specific susceptibility to aging. Clin. Immunol., 127: 107-118. DOI: $10.1016 /$ j.clim.2007.12.002

Dauguet, N., C. Recher, C. Demur, J.J. Fournie and M. Poupot et al., 2011. Pre-eminence and persistence of immature natural killer cells in acute myeloid leukemia patients in first complete remission. Am. J. Hematol., 86: 209-213. DOI: 10.1002/ajh.21906

De Sanctis, F., S. Solito, S. Ugel, B. Molon and V. Bronte et al., 2016. MDSCs in cancer: Conceiving new prognostic and therapeutic targets. Biochim. Biophys. Acta, 1865: 35-48.

DOI: 10.1016/j.bbcan.2015.08.001 
Deruy, E., J. Nassour, N. Martin, C. Vercamer and N. Malaquin et al., 2014. Level of macroautophagy drives senescent keratinocytes into cell death or neoplastic evasion. Cell Death Dis., 5: e1577-e1577. DOI: 10.1038/cddis.2014.533

Di Lorenzo, G., C.R. Balistreri, G. Candore, D. Cigna, A. Colombo, G.C. Romano et al., 1999. Granulocyte and natural killer activity in the elderly. Mech. Age. Dev., 108: 25-38.

DOI: $10.1016 / \mathrm{S} 0047-6374(98) 00156-0$

Dobrzanski, M.J., 2013. Expanding roles for CD4 T cells and their subpopulations in tumor immunity and therapy. Frontiers Oncol., 3: 63-63. DOI: 10.3389 /fonc. 2013.00063

Dunn, G.P., A.T. Bruce, H. Ikeda, L.J. Old and R.D. Schreiber, 2002. Cancer immunoediting: From immunosurveillance to tumor escape. Nat. Immunol., 3: 991-998. DOI: 10.1038/ni1102-991

Eaton, S.M., E.M. Burns, K. Kusser, T.D. Randall and L. Haynes, 2004. Age-related defects in CD4 T cell cognate helper function lead to reductions in humoral responses. J. Exp. Med., 200: 1613-1622. DOI: $10.1084 /$ jem.20041395

Effros, R.B., 2010. Telomere/telomerase dynamics within the human immune system: Effect of chronic infection and stress. Exp. Gerontol., 46: 135-140. DOI: 10.1016/j.exger.2010.08.027

Ehninger, A. and A. Trumpp, 2011. The bone marrow stem cell niche grows up: Mesenchymal stem cells and macrophages move in. J. Exp. Med., 208: 421-8. DOI: $10.1084 /$ jem.20110132

Eliasson, P., M. Rehn, P. Hammar, P. Larsson and O. Sirenko et al., 2010. Hypoxia mediates low cellcycle activity and increases the proportion of longterm-reconstituting hematopoietic stem cells during in vitro culture. Exp. Hematol., 38: 301-310.e302. DOI: 10.1016/j.exphem.2010.01.005

Farag, S.S., J.B. Van Deusen, T.A. Fehniger and M.A. Caligiuri, 2003. Biology and clinical impact of human natural killer cells. Int. J. Hematol., 78: 7-17. DOI: 10.1007/BF02983234

Farnault, L., C. Sanchez, C. Baier, T. Le Treut and R.T. Costello, 2012. Hematological malignancies escape from NK cell innate immune surveillance: Mechanisms and therapeutic implications. Clin. Dev. Immunol., 2012: 421702-421702. DOI: $10.1155 / 2012 / 421702$

Fauriat, C., S. Just-Landi, F. Mallet, C. Arnoulet and D. Sainty et al., 2007. Deficient expression of NCR in NK cells from acute myeloid leukemia: Evolution during leukemia treatment and impact of leukemia cells in $\mathrm{NCR}^{\text {dull }}$ phenotype induction. Blood, 109: 323-330. DOI: 10.1182/blood-2005-08-027979
Feldman, N., A. Rotter-Maskowitz and E. Okun, 2015. DAMPs as mediators of sterile inflammation in aging-related pathologies. Age. Res. Rev., 24: 29-39. DOI: $10.1016 /$ j.arr.2015.01.003

Foster, A.D., A. Sivarapatna and R.E. Gress, 2011. The aging immune system and its relationship with cancer. Ag. Health, 7: 707-718. DOI: $10.2217 /$ ahe. 11.56

Fouad, Y.A. and C. Aanei, 2017. Revisiting the hallmarks of cancer. Am. J. Cancer Res., 7: 1016-1036. PMID: 28560055

Franceschi, C., M. Capri, D. Monti, S. Giunta and F. Olivieri et al., 2007. Inflammaging and antiinflammaging: A systemic perspective on aging and longevity emerged from studies in human. Mech. Age. Dev., 128: 92-105.

DOI: 10.1016/j.mad.2006.11.016

Franceschi, C. and J. Campisi, 2014. Chronic inflammation (inflammaging) and its potential contribution to age-associated diseases. J. Gerontol. A, 69: 4-9. DOI: 10.1093/gerona/glu057

Francisco, L.M., V.H. Salinas, K.E. Brown, V.K. Vanguri and G.J. Freeman et al., 2009. PD-L1 regulates the development, maintenance and function of induced regulatory T cells. J. Exp. Med., 206: 3015-3029. DOI: 10.1084/jem.20090847

Fulop, T., A. Larbi, R. Kotb and G. Pawelec, 2013. Immunology of aging and cancer development. Cancer Ag., 38: 38-48. DOI: 10.1159/000343599

Fulop, T., R. Kotb, C.F. Fortin, G. Pawelec and F. de Angelis et al., 2010. Potential role of immunosenescence in cancer development. Annals New York Acad. Sci., 1197: 158-65. DOI: $10.1111 /$ j.1749-6632.2009.05370.x

Gabrilovich, D.I., 2017. Myeloid-Derived Suppressor Cells. Cancer Immunol. Res., 5: 3-8.

DOI: 10.1158/2326-6066.CIR-16-0297

Garbe, K., K. Bratke, S. Wagner, J.C. Virchow and M. Lommatzsch, 2012. Plasmacytoid dendritic cells and their Toll-like receptor 9 expression selectively decrease with age. Human Immunol., 73: 493-497. DOI: 10.1016/j.humimm.2012.02.007

Gardai, S.J., K.A. Mc-Phillips, S.C. Frasch, W.J. Janssen and A. Starefeldt et al., 2005. Cell-surface calreticulin initiates clearance of viable or apoptotic cells through trans-activation of LRP on the phagocyte. Cell, 123: 321-34. DOI: $10.1016 /$ j.cell.2005.08.032

Giles, A.J., C.D. Chien, C.M. Reid, T.J. Fry and D.M. Park et al., 2016. The functional interplay between systemic cancer and the hematopoietic stem cell niche. Pharmacol. Therapeut., 168: 53-60. DOI: 10.1016/j.pharmthera.2016.09.006 
Gilliet, M., W. Cao and Y.J. Liu, 2008. Plasmacytoid dendritic cells: Sensing nucleic acids in viral infection and autoimmune diseases. Nat. Rev. Immunol., 8: 594-606. DOI: 10.1038/nri2358

Godder, K.T., P.J. Henslee-Downey, J. Mehta, B.S. Park and K.Y. Chiang et al,. 2007. Long term diseasefree survival in acute leukemia patients recovering with increased $\gamma \delta \mathrm{T}$ cells after partially mismatched related donor bone marrow transplantation. Bone Marrow Transplant., 39: 751-757. DOI: $10.1038 /$ sj.bmt. 1705650

Golden, E.B., I. Pellicciotta, S. Demaria, M.H. BarcellosHoff and S.C. Formenti, 2012. The convergence of radiation and immunogenic cell death signaling pathways. Frontiers Oncol., 2: 88-88.

DOI: $10.3389 /$ fonc. 2012.00088

Gomez, C.R., E.D. Boehmer and E.J. Kovacs, 2005. The aging innate immune system. Curr. Opin. Immunol., 17: 457-462. DOI: 10.1016/j.coi.2005.07.013

Gondek, D.C., L.F. Lu, S.A. Quezada, S. Sakaguchi and R.J. Noelle, 2005. Cutting edge: Contact-mediated suppression by CD4+ CD25+ regulatory cells involves a granzyme B-dependent, perforin-independent mechanism. J. Immunol., 174: 1783-1786.

DOI: $10.4049 /$ jimmunol.174.4.1783

Gorczynski, R.M., L. Lee and I. Boudakov, 2005. Augmented induction of CD4+CD25+ Treg using monoclonal antibodies to CD200R. Transplantation, 79: $1180-1183$.

DOI: 10.1097/01.TP.0000152118.51622.F9

Granger, A., R. Mott and N. Emambokus, 2016. Is aging as inevitable as death and taxes? Cell Metabolism, 23: 947-948. DOI: 10.1016/j.cmet.2016.06.003

Grosso, D.A., R.C. Hess and M.A. Weiss, 2015. Immunotherapy in acute myeloid leukemia. Cancer, 121: 2689-704. DOI: 10.1002/cncr.29378

Gyorki, D.E., M.L. Asselin-Labat, N. van Rooijen, G.J. Lindeman and J.E. Visvader, 2009. Resident macrophages influence stem cell activity in the mammary gland. Breast Cancer Res., 11: R62-R62. DOI: $10.1186 /$ bcr2353

Haabeth, O.A., K.B. Lorvik, C. Hammarstrm, I.M. Donaldson and G. Haraldsen et al., 2011. Inflammation driven by tumour-specific Th1 cells protects against B-cell cancer. Nature Commun., 2: 240-240. DOI: 10.1038/ncomms 1239

Hakim, F.T. and R.E. Gress, 2007. Immunosenescence: Deficits in adaptive immunity in the elderly. Tissue Antigens, 70: 179-189. DOI: $10.1111 / \mathrm{j} .1399-0039.2007 .00891 . x$

Hanahan, D. and R.A. Weinberg, 2011. Hallmarks of cancer: The next generation. Cell, 144: 646-674. DOI: $10.1016 /$ j.cell.2011.02.013
Hazeldine, J., P. Hampson and J.M. Lord, 2012. Reduced release and binding of perforin at the immunological synapse underlies the age-related decline in natural killer cell cytotoxicity. Ag. Cell, 11: 751-759.

DOI: $10.1111 /$ j.1474-9726.2012.00839.x

Henry, C.J., A.A. Marusyk and J. De Gregori, 2011. Aging-associated changes in hematopoiesis and leukemogenesis: What's the connection? Aging, 3: 643-656. DOI: 10.18632/aging. 100351

Hodes, R.J., K.S. Hathcock and N.P. Weng, 2002. Telomeres in T and B cells. Nat. Rev. Immunol., 2: 699-706. DOI: $10.1038 /$ nri890

Iida, T., M. Iwahashi, M. Katsuda, K. Ishida and M. Nakamori et al., 2011. Tumor-infiltrating CD4+ Th17 cells produce IL-17 in tumor microenvironment and promote tumor progression in human gastric cancer. Oncol. Rep., 25: 1271-1277. DOI: 10.3892/or.2011.1201

Ismail, M.M. and N.A. Abdulateef, 2017. Bone marrow Tcell percentage: A novel prognostic indicator in acute myeloid leukemia. Int. J. Hematol., 105: 453-464. DOI: $10.1007 / \mathrm{s} 12185-016-2153-5$

Iwasaki, H. and T. Suda, 2010. Hematopoietic Stem Cells and Their Niche. In: Hematopoietic Stem Cell Biology, Kondo, M. (Ed.), Humana Press, Springer Nature, pp: 37-55.

Jia, W., C. Jackson-Cook and M.R. Graf, 2010. Tumorinfiltrating, myeloid-derived suppressor cells inhibit $\mathrm{T}$ cell activity by nitric oxide production in an intracranial rat glioma + vaccination model. J. Neuroimmunol., 223: 20-30.

DOI: 10.1016/j.jneuroim.2010.03.011

Jing, H. and S. Lee, 2014. NF-кB in cellular senescence and cancer treatment. Molecules Cells, 37: 189-195. DOI: $10.14348 /$ molcells.2014.2353

Jones, S.A., J. Scheller and S. Rose-John, 2011. Therapeutic strategies for the clinical blockade of IL-6/gp130 signaling. J. Clin. Invest., 121: 3375-83. DOI: $10.1172 /$ JCI57158

Karin, M., T. Lawrence and V. Nizet, 2006. Innate immunity gone awry: Linking microbial infections to chronic inflammation and cancer. Cell, 124: 823-835. DOI: $10.1016 /$ j.cell.2006.02.016

Keating, S.E., M. Baran and A.G. Bowie, 2011. Cytosolic DNA sensors regulating type I interferon induction. Trends Immunol., 32: 574-581. DOI: $10.1016 /$ j.it.2011.08.004

Kilpatrick, R.D., T. Rickabaugh, L.E. Hultin, P. Hultin and M.A. Hausner et al., 2008. Homeostasis of the naive $\mathrm{CD} 4+\mathrm{T}$ cell compartment during aging. J. Immunol., 180: 1499-1507. DOI: $10.4049 /$ jimmunol.180.3.1499 
Kim, R., M. Emi and K.Tanabe, 2007. Cancer immunoediting from immune surveillance to immune escape. Immunology, 121: 1-14. DOI: $10.1111 / \mathrm{j} .1365-2567.2007 .02587 . x$

Korkaya, H., S. Liu and M.S. Wicha, 2011. Regulation of cancer stem cells by cytokine networks: Attacking cancer's inflammatory roots. Clin. Cancer Res., 17: 6125-6129. DOI: 10.1158/1078-0432.CCR-10-2743

Lai, Y.P., C.J. Jeng and S.C. Chen, 2011. The roles of CD4+ T cells in tumor immunity. ISRN Immunol., 2011: 497397-497397. DOI: 10.5402/2011/497397

Le Dieu, R., D.C. Taussig, A.G. Ramsay, R. Mitter and F. Miraki-Moud et al., 2009. Peripheral blood T cells in Acute Myeloid Leukemia (AML) patients at diagnosis have abnormal phenotype and genotype and form defective immune synapses with AML blasts. Blood, 114: 3909-3916. DOI: 10.1182/blood-2009-02-206946

Le Jeune, C., S. Bertoli, M. Elhamri, F. Vergez and C. Borel et al., 2014. Initial absolute lymphocyte count as a prognostic factor for outcome in acute myeloid leukemia. Leukemia Lymphoma, 55: 855-862.

DOI: $10.3109 / 10428194.2013 .813504$

Li, L. and W.B. Neaves, 2006. Normal stem cells and cancer stem cells: The niche matters. Cancer Res., 66: 4553-7. 10.1158/0008-5472.CAN-05-3986

Lion, E., Y. Willemen, Z.N. Berneman, V.F. Van Tendeloo and E.L. Smits, 2012. Natural killer cell immune escape in acute myeloid leukemia. Leukemia, 26: 2019-2026. DOI: 10.1038/leu.2012.87

Liu, S. and D. Zheng, 2012. Dysregulated expression of miR-146a contributes to age-related dysfunction of macrophages. Ag. Cell, 11:29-40. DOI: $10.1111 / \mathrm{j} .1474-9726.2011 .00757 . \mathrm{x}$

Liu, Y.J., 2001. Dendritic cell subsets and lineages and their functions in innate and adaptive immunity. Cell, 106: 259-62. DOI: $10.1016 / \mathrm{S} 0092-8674(01) 00456-1$

Majeti, R., 2011. Monoclonal antibody therapy directed against human acute myeloid leukemia stem cells. Oncogene, 30: 1009-1019. DOI: 10.1038/onc.2010.511

Majeti, R., M.P. Chao, A.A. Alizadeh, W.W. Pang, S. Jaiswal, K.D. Gibbs et al. 2009. CD47 is an adverse prognostic factor and therapeutic antibody target on human acute myeloid leukemia stem cells. Cell, 138: 286-99. DOI: 10.1016/j.cell.2009.05.045

Malaguarnera, L., E. Cristaldi and M. Malaguarnera, 2010. The role of immunity in elderly cancer. Critical Rev. Oncol. Hematol., 74: 40-60. DOI: 10.1016/j.critrevonc.2009.06.002

Malek, E., M. de Lima, J.J. Letterio, B.G. Kim and J.H. Finke et al., 2016. Myeloid-derived suppressor cells: The green light for myeloma immune escape. Blood Rev., 30: 341-348. DOI: 10.1016/j.blre.2016.04.002
Mariani, E., A.R. Mariani, A. Meneghetti, A. Tarozzi and L. Cocco et al., 1998. Age-dependent decreases of NK cell phosphoinositide turnover during spontaneous but not Fc-mediated cytolytic activity. Int. J. Immunol., 10: 981-989. DOI: 10.1093/intimm/10.7.981

Meirow, Y., J. Kanterman and M. Baniyash, 2015. Paving the road to tumor development and spreading: Myeloid-derived suppressor cells are ruling the fate. Frontiers Immunol., 6: 523-523. DOI: $10.3389 /$ fimmu.2015.00523

Mellor, A.L. and D.H. Munn, 2004. IDO expression by dendritic cells: Tolerance and tryptophan catabolism. Nat. Rev. Immunol., 4: 762-774. DOI: $10.1038 /$ nri1457

Meyer, C., A. Sevko, M. Ramacher, A.V. Bazhin and C.S. Falk et al., 2011. Chronic inflammation promotes myeloid-derived suppressor cell activation blocking antitumor immunity in transgenic mouse melanoma model. Proc. Nat. Acad. Sci. USA, 108: 17111-17116. DOI: 10.1073/pnas. 1108121108

Mills, C.D., 2012. M1 and M2 Macrophages: Oracles of Health and Disease. Critical Rev. Immunol., 32: 463-88. DOI: 10.1615/CritRevImmunol.v32.i6.10

Mohammadi, M., Y. Cao, I. Glimelius, M. Bottai and S. Eloranta et al., 2015. The impact of comorbid disease history on all-cause and cancer-specific mortality in myeloid leukemia and myeloma - a Swedish population-based study. BMC Cancer, 15: 850-850. DOI: $10.1186 / \mathrm{s} 12885-015-1857-\mathrm{x}$

Montoya-Or Tiz, G., 2013. Immunosenescence, aging and systemic lupus erythematous. Autoimmune Dis., 2013: 267078-267078. DOI: 10.1155/2013/267078

Motallebnezhad, M., F. Jadidi-Niaragh, E.S. Qamsari, S. Bagheri and T. Gharibi et al., 2016. The immunobiology of myeloid-derived suppressor cells in cancer. Tumour Biol., 37: 1387-1406. DOI: $10.1007 / \mathrm{s} 13277-015-4477-9$

Musuraca, G., S. De-Matteis, R. Napolitano, C. Papayannidis and V. Guadagnuolo et al., 2015. IL17/IL-10 double-producing $\mathrm{T}$ cells: New link between infections, immunosuppression and acute myeloid leukemia. J. Translat. Med., 13: 229-229. DOI: $10.1186 / \mathrm{s} 12967-015-0590-1$

NCI, 2017. SEER stat fact sheets. National Cancer Institute.

Norde, W.J., F. Maas, W. Hobo, A. Korman and M. Quigley et al., 2011. PD-1/PD-L1 interactions contribute to functional T-cell impairment in patients who relapse with cancer after allogeneic stem cell transplantation. Cancer Res., 71: 5111-5122. DOI: 10.1158/0008-5472.CAN-11-0108

Ochsenbein, A.F., S. Sierro, B. Odermatt, M. Pericin and U. Karrer et al., 2001. Roles of tumour localization, second signals and cross priming in cytotoxic T-cell induction. Nature, 411: 1058-1064.

DOI: $10.1038 / 35082583$ 
Ohta, A. and M. Sitkovsky, 2014. Extracellular adenosine-mediated modulation of regulatory $\mathrm{T}$ cells. Frontiers Immunol., 5: 304-304. DOI: $10.3389 /$ fimmu.2014.00304

Olsnes, A.M., A. Ryningen, E. Ersvaer and O. Bruserud, 2008. In vitro induction of a dendritic cell phenotype in primary human acute myelogenous leukemia (AML) blasts alters the chemokine release profile and increases the levels of T cell chemotactic CCL17 and CCL22. J. Interferon Cytokine Res., 28: 297-310. DOI: 10.1089/jir.2007.0052

Onishi, H., T. Morisaki, E. Baba, H. Kuga and H. Kuroki et al., 2002. Dysfunctional and short-lived subsets in monocyte-derived dendritic cells from patients with advanced cancer. Clin. Immunol., 105: 286-295. DOI: $10.1006 / \mathrm{clim} .2002 .5293$

Orford, K.W. and D.T. Scadden, 2008. Deconstructing stem cell self-renewal: Genetic insights into cellcycle regulation. Nat. Rev. Genet., 9: 115-128.

DOI: $10.1038 / \mathrm{nrg} 2269$

Ouyang, X., Z. Yang, R. Zhang, P. Arnaboldi and G. Lu et al., 2011. Potentiation of Th17 cytokines in aging process contributes to the development of colitis. Cellular Immunol., 266: 208-217.

DOI: $10.1016 /$ j.cellimm.2010.10.007

Ozkazanc, D., D. Yoyen-Ermis, E. Tavukcuoglu, Y. Buyukasik and G. Esendagli, 2016. Functional exhaustion of $\mathrm{CD} 4+\mathrm{T}$ cells induced by costimulatory signals from myeloid leukaemia cells. Immunology, 149: 460-471. DOI: $10.1111 / \mathrm{imm} .12665$

Panda, A., A. Arjona, E. Sapey, F. Bai and E. Fikrig et al., 2009. Human innate immunosenescence: Causes and consequences for immunity in old age. Trends Immunol., 30: 325-333. DOI: 10.1016/j.it.2009.05.004

Panda, A., F. Qian, S. Mohanty, D. van Duin and F.K. Newman et al., 2010. Age-associated decrease in TLR function in primary human dendritic cells predicts influenza vaccine response. J. Immunol., 184: 2518-2527. DOI: 10.4049/jimmunol.0901022

Pandiyan, P., L. Zheng, S. Ishihara, J. Reed and M.J. Lenardo, 2007. CD4+ CD25+ Foxp3+ regulatory T cells induce cytokine deprivation-mediated apoptosis of effector CD4+T cells. Nat. Immunol., 8: 1353-1362. DOI: 10.1038/ni1536

Pang, W.W., S.L. Schrier and I.L. Weissman, 2017. Age-associated changes in human hematopoietic stem cells. Seminars Hematol., 54: 39-42. DOI: 10.1053/j.seminhematol.2016.10.004

Parish, S.T., J.E. Wu and R.B. Effros, 2010a. Sustained CD28 expression delays multiple features of replicative senescence in human CD8 $\mathrm{T}$ lymphocytes. J. Clin. Immunol., 30: 798-805. DOI: $10.1007 / \mathrm{s} 10875-010-9449-7$
Parish, S.T., S. Kim, R.K. Sekhon, J.E. Wu and Y. Kawakatsu et al., 2010b. Adenosine deaminase modulation of telomerase activity and replicative senescence in human CD8 $\mathrm{T}$ lymphocytes. J. Immunol., 184: 2847-2854. DOI: 10.4049/jimmunol.0903647

Parker, K.H., D.W. Beury and S. Ostrand-Rosenberg, 2015. Myeloid-derived suppressor cells: Critical cells driving immune suppression in the tumor microenvironment. Adv. Cancer Res., 128: 95-139. DOI: $10.1016 /$ bs.acr.2015.04.002

Piccinini, A.M. and K.S. Midwood, 2010. DAMPening inflammation by modulating TLR signalling. Mediators Inflammat., 2010: 672395-672395. DOI: $10.1155 / 2010 / 672395$

Pleyer, L., P. Valent and R. Greil, 2016. Mesenchymal Stem and Progenitor Cells in Normal and Dysplastic Hematopoiesis-Masters of Survival and Clonality? Int. J. Molecular Sci., 17: E1009-E1009. DOI: $10.3390 /$ ijms 17071009

Plowden, J., M. Renshaw-Hoelscher, S. Gangappa, C. Engleman and J.M. Katz et al., 2004. Impaired antigen-induced $\mathrm{CD} 8+\mathrm{T}$ cell clonal expansion in aging is due to defects in antigen presenting cell function. Cellular Immunol., 229: 86-92. DOI: $10.1016 /$ j.cellimm.2004.07.001

Poli, A., T. Michel, M. Theresine, E. Andres and F. Hentgesv et al., 2009. CD56 $6^{\text {bright }}$ Natural Killer (NK) cells: An important NK cell subset. Immunology, 126: 458-465. DOI: $10.1111 / \mathrm{j} .1365-2567.2008 .03027 . \mathrm{x}$

Pollyea, D.A., H.E. Kohrt and B.C. Medeiros, 2011. Acute myeloid leukaemia in the elderly: A review. Brit. J. Haematol., 152: 524-542. DOI: $10.1111 /$ j.1365-2141.2010.08470.x

Rainham, D.G., C.J. Bates, C.M. Blanchard, T.J. Dummer and S.F. Kirk et al., 2012. Spatial classification of youth physical activity patterns. Am. J. Preventive Med., 42: e87-e96.

DOI: 10.1016/j.amepre.2012.02.011

Rosenstiel, P., S. Derer, A. Till, R. Hasler and H. Eberstein et al., 2008. Systematic expression profiling of innate immune genes defines a complex pattern of immunosenescence in peripheral and intestinal leukocytes. Genes Immunity, 9: 103-114. DOI: $10.1038 /$ sj.gene.6364454

Rossi, D.J., D. Bryder and I.L. Weissman, 2007. Hematopoietic stem cell aging: Mechanism and consequence. Exp. Gerontol., 42: 385-390. DOI: 10.1016/j.exger.2006.11.019

Rubartelli, A. and M.T. Lotze, 2007. Inside, outside, upside down: Damage-Associated MolecularPattern molecules (DAMPs) and redox. Trends Immunol., 28: 429-436.

DOI: $10.1016 /$ j.it.2007.08.004 
Rubnitz, J.E., H. Inaba, R.C. Ribeiro, S. Pounds and B. Rooney et al., 2010. NKAML: A pilot study to determine the safety and feasibility of haploidentical natural killer cell transplantation in childhood acute myeloid leukemia. J. Clin. Oncolol., 28: 955-959. DOI: $10.1200 /$ JCO.2009.24.4590

Sadeghi, H.M., J.F. Schnelle, J.K. Thoma, P. Nishanian and J.L. Fahey, 1999. Phenotypic and functional characteristics of circulating monocytes of elderly persons. Exp. Gerontol., 34: 959-970.

DOI: 10.1016/S0531-5565(99)00065-0

Sandoval-Borrego, D., M.C. Moreno-Lafont, E.A. Vazquez-Sanchez, A. Gutierrez-Hoya and R. LpezSantiago et al., 2016. Overexpression of CD158 and NKG2A inhibitory receptors and underexpression of NKG2D and NKp46 activating receptors on NK cells in acute myeloid leukemia. Arch. Med. Res., 47: 55-64. DOI: 10.1016/j.arcmed.2016.02.001

Schick, J., V. Vogt, M. Zerwes, T. Kroell and D. Kraemer et al., 2013. Antileukemic T-cell responses can be predicted by the composition of specific regulatory T-cell subpopulations. J. Immunotherapy, 36: 223-237. DOI: 10.1097/CJI.0b013e31829180e7

Schneider, V., L. Zhang, M. Rojewski, N. Fekete and H. Schrezenmeier et al., 2015. Leukemic progenitor cells are susceptible to targeting by stimulated cytotoxic $\mathrm{T}$ cells against immunogenic leukemiaassociated antigens. Int. J. Cancer, 137: 2083-2092. DOI: $10.1002 /$ ijc. 29583

Schreiber, R.D., L.J. Old and M.J. Smyth, 2011. Cancer immunoediting: Integrating immunity's roles in cancer suppression and promotion. Science, 331: 1565-1570. DOI: $10.1126 /$ science. 1203486

Schroeder, T., S. Geyh, U. Germing and R. Haas, 2016. Mesenchymal stromal cells in myeloid malignancies. Blood Res., 51: 225-232.

DOI: $10.5045 /$ br.2016.51.4.225

Schuurhuis, D.H., N. Fu, F. Ossendorp and C.J. Melief, 2006. Ins and outs of dendritic cells. Int. Arch. Allergy Immunol., 140: 53-72. DOI: 10.1159/000092002

Sempowski, G.D., M.E. Gooding, H.X. Liao, P.T. Le and B.F. Haynes, 2001. T cell receptor excision circle assessment of thymopoiesis in aging mice. Molecular Immunol., 38: 841-848.

DOI: 10.1016/S0161-5890(01)00122-5

Shaw, A.C., D.R. Goldstein and R.R. Montgomery, 2013. Age-dependent dysregulation of innate immunity. Nat. Rev. Immunol., 13: 875-887. DOI: $10.1038 /$ nri3547

Shaw, A.C., S. Joshi, H. Greenwood, A. Panda and J.M. Lord, 2010. Aging of the innate immune system. Curr. Opin. Immunol., 22: 507-513.

DOI: $10.1016 /$ j.coi.2010.05.003
Shi, L., S. Chen, L. Yang and Y. Li, 2013. The role of PD-1 and PD-L1 in T-cell immune suppression in patients with hematological malignancies. J. Hematol. Oncol., 6: 74-74. DOI: $10.1186 / 1756-8722-6-74$

Shurin, G.V., C.E. Ouellette and M.R. Shurin, 2012. Regulatory dendritic cells in the tumor immunoenvironment. Cancer Immunol. Immunotherapy, 61: 223-230. DOI: $10.1007 / \mathrm{s} 00262-011-1138-8$

Shurin, M.R., H. Naiditch, H. Zhong and G.V. Shurin, 2011. Regulatory dendritic cells: New targets for cancer immunotherapy. Cancer Biol. Therapy, 11: 988-992. DOI: 10.4161/cbt.11.11.15543

Siegler, U., C.P. Kalberer, P. Nowbakht, S. Sendelov and S. Meyer-Monard et al., 2005. Activated natural killer cells from patients with acute myeloid leukemia are cytotoxic against autologous leukemic blasts in NOD/SCID mice. Leukemia, 19: 2215-2222. DOI: $10.1038 /$ sj.leu.2403985

Silberstein, L., K.A. Goncalves, P.V. Kharchenko, R. Turcotte and Y. Kfoury et al., 2016. Proximitybased differential single-cell analysis of the niche to identify stem/progenitor cell regulators. Cell Stem Cell, 19: 530-543. 10.1016/j.stem.2016.07.004

Smyth, M.J., E. Cretney, J.M. Kelly, J.A. Westwood and S.E. Street et al., 2005. Activation of NK cell cytotoxicity. Molecular Immunol., 42: 501-510. DOI: 10.1016/j.molimm.2004.07.034

Solana, R., R. Tarazona, I. Gayoso, O. Lesur and G. Dupuis et al., 2012. Innate immunosenescence: Effect of aging on cells and receptors of the innate immune system in humans. Seminars Immunol., 24: 331-341. DOI: 10.1016/j.smim.2012.04.008

Sportès, C. and F.T. Hakim, 2009. Aging, Immunity and Cancer. In: Handbook on Immunosenescence: Basic Understanding and Clinical Applications, Fulop, T., C. Franceschi, K. Hirokawa and G. Pawelec (Eds.), Springer, Berlin, Germany, pp: 1119-1138.

Steinbrink, K., K. Mahnke, S. Grabbe, A.H. Enk and H. Jonuleit, 2009. Myeloid dendritic cell: From sentinel of immunity to key player of peripheral tolerance? Human Immunol., 70: 289-293. DOI: $10.1016 /$ j.humimm.2009.02.003

Steinman, R.M., D. Hawiger and M.C. Nussenzweig, 2003. Tolerogenic dendritic cells. Annual Rev. Immunol., 21: 685-711.

DOI: 10.1146/annurev.immunol.21.120601.141040

Stout-Delgado, H.W., X. Yang, W.E. Walker, B.M. Tesar and D.R. Gold Stein, 2008. Aging impairs IFN regulatory factor 7 up-regulation in plasmacytoid dendritic cells during TLR9 activation. J. Immunol., 181: 6747-6756.

DOI: 10.4049/jimmunol.181.10.6747 
Strohacker, K., W.L. Breslin, K.C. Carpenter and B.K. McFarlin, 2012. Aged mice have increased inflammatory monocyte concentration and altered expression of cell-surface functional receptors. J. Biosci., 37: 55-62. DOI: 10.1007/s12038-011-9169-z

Strowig, T., J. Henao-Mejia, E. Elinav and R. Flavell, 2012. Inflammasomes in health and disease. Nature, 481: 278-286. DOI: 10.1038/nature 10759

Subramanian, S., E.T. Boder and D.E. Discher, 2007. Phylogenetic divergence of CD47 interactions with human signal regulatory protein $\alpha$ reveals locus of species specificity: Implications for the binding site. J. Biol. Chem., 282: 1805-1818. DOI: $10.1074 /$ jbc.M603923200

Sun, H., Y. Li, Z.F. Zhang, Y. Ju and L. Li et al., 2015. Increase in Myeloid-Derived Suppressor Cells (MDSCs) associated with Minimal Residual Disease (MRD) detection in adult acute myeloid leukemia. Int. J. Hematol., 102: 579-586. DOI: $10.1007 / \mathrm{s} 12185-015-1865-2$

Szczepanski, M.J., M. Szajnik, M. Czystowska, M. Mandapathil and L. Strauss et al., 2009. Increased frequency and suppression by regulatory $\mathrm{T}$ cells in patients with acute myelogenous leukemia. Clin. Cancer Res., 15: 3325- 3332.

DOI: $10.1158 / 1078-0432 . C C R-08-3010$

Tadokoro, C.E., G. Shakhar, S. Shen, Y. Ding and A.C. Lino et al., 2006. Regulatory $\mathrm{T}$ cells inhibit stable contacts between CD4+ T cells and dendritic cells in vivo. J. Expe. Med., 203: 505-511. DOI: $10.1084 /$ jem.20050783

Takubo, K., N. Goda, W. Yamada, H. Iriuchishima and E. Ikeda et al., 2010. Regulation of the HIF-1alpha level is essential for hematopoietic stem cells. Cell Stem Cell, 7: 391-402. DOI: $10.1016 /$ j.stem.2010.06.020

Tao, Q., Y. Pan, Y. Wang, H. Wang and S. Xiong et al., 2015. Regulatory $\mathrm{T}$ cells-derived IL-35 promotes the growth of adult acute myeloid leukemia blasts. Int. J. Cancer, 137: 2384-2393.

DOI: $10.1002 /$ ijc. 29563

Taube, J.M., R.A. Anders, G.D. Young, H. Xu and R. Sharma et al., 2012. Colocalization of inflammatory response with B7-H1 expression in human melanocytic lesions supports an adaptive resistance mechanism of immune escape. Sci. Translat. Med. J., 4: 127-137. DOI: 10.1126/scitranslmed.3003689

Teague, R.M. and J. Kline, 2013. Immune evasion in acute myeloid leukemia: Current concepts and future directions. J. ImmunoTherapy Cancer, 1: 13-13. DOI: $10.1186 / 2051-1426-1-13$

Thornton, A.M., E.E. Donovan, C.A. Piccirillo and E.M. Shevach, 2004. Cutting edge: IL-2 is critically required for the in vitro activation of $\mathrm{CD} 4+\mathrm{CD} 25+\mathrm{T}$ cell suppressor function. J. Immunol., 172: 6519-6523.

DOI: $10.4049 /$ jimmunol.172.11.6519
Tonks, A., R. Hills, P. White, B. Rosie and K.I. Mills et al., 2007. CD200 as a prognostic factor in acute myeloid leukaemia. Leukemia, 21: 566-568.

DOI: $10.1038 /$ sj.leu.2404559

Tsukamoto, H., G.E. Huston, J. Dibble, D.K. Duso and S.L. Swain, 2010. Bim dictates naive CD4 T cell lifespan and the development of age-associated functional defects. J. Immunol., 185: 4535-4544. DOI: $10.4049 /$ jimmunol.1001668

Tsukamoto, H., K. Clise-Dwyer, G.E. Huston, D.K. Duso and A.L. Buck et al., 2009. Age-associated increase in lifespan of naïve CD4 T cells contributes to T-cell homeostasis but facilitates development of functional defects. Proc. Nat. Acad. Sci., 106: 18333-18338. DOI: 10.1073/pnas.0910139106

Ustun, C., J.S. Miller, D.H. Munn, D.J. Weisdorf and B.R. Blazar, 2011. Regulatory $\mathrm{T}$ cells in acute myelogenous leukemia: Is it time for immunomodulation? Blood, 118: 5084-5095. DOI: 10.1182/blood-2011-07-365817

Van Duin, D., H.G. Allore, S. Mohanty, S. Ginter and F.K. Newman et al., 2007. Prevaccine determination of the expression of costimulatory B7 molecules in activated monocytes predicts influenza vaccine responses in young and older adults. J. Infect. Dis., 195: 1590-1597. DOI: 10.1086/516788

Verheyden, S., M. Bernier and C. Demanet, 2004. Identification of natural killer cell receptor phenotypes associated with leukemia. Leukemia, 18: 2002-2007. DOI: 10.1038/sj.leu.2403525

Vey, N., J.H. Bourhis, N. Boissel, D. Bordessoule and T. Prebet et al., 2012. A phase 1 trial of the antiinhibitory KIR mAb IPH2101 for AML in complete remission. Blood, 120: 4317-4323.

DOI: $10.1182 /$ blood-2012-06-437558

Wang, X., S. Huang and J.L. Chen, 2017. Understanding of leukemic stem cells and their clinical implications. Molecular Cancer, 16: 2-2. DOI: 10.1186/s12943-016-0574-7

Wang, Y., C. Chen, F. Dong, S. Ma and J. Xu et al., 2015. NK cells play a significant role in immunosurveillance at the early stage of MLL-AF9 acute myeloid leukemia via CD226/CD155 interactions. China Life Sci., 58: 1288-1298. DOI: $10.1007 / \mathrm{s} 11427-015-4968-3$

Watanabe, M.A., J.M. Oda, M.K. Amarante and J. Cesar Voltarelli, 2010. Regulatory $\mathrm{T}$ cells and breast cancer: Implications for immunopathogenesis. Cancer Metastasis Rev., 29: 569-579. DOI: $10.1007 / \mathrm{s} 10555-010-9247-\mathrm{y}$

Wherry, J. and M. Kurachi, 2015. Molecular and cellular insights into T cell exhaustion. Nat. Rev. Immunol., 15: 486-499. DOI: $10.1038 /$ nri3862 
Whiteside, T.L., 2010. Immune responses to malignancies. J. Allergy Clin. Immunol., 125: 272-83. DOI: 10.1016/j.jaci.2009.09.045

Wilke, C.M., I. Kryczek, S. Wei, E. Zhao and K. Wu et al., 2011. Th17 cells in cancer: Help or hindrance? Carcinogenesis, 32: 643-649. DOI: $10.1093 /$ carcin/bgr019

Wilson, E.B., J.J. El-Jawhari, A.L. Neilson, G.D. Hall and A.A. Melcher et al., 2011. Human tumour immune evasion via TGF- $\beta$ blocks NK cell activation but not survival allowing therapeutic restoration of anti-tumour activity. PLoS. One, 6: e22842-e22842. DOI: 10.1371/journal.pone.0022842

Woolthuis, C.M., G. de-Haan and G. Huls, 2011. Aging of hematopoietic stem cells: Intrinsic changes or micro-environmental effects? Curr. Opin. Immunol., 23: 512-517. DOI: 10.1016/j.coi.2011.05.006

Xiang, M., L. Guo, Y. Ma and Y. Li, 2016. Expression of Th17 and CD4+ CD25+ $\mathrm{T}$ regulatory cells in peripheral blood of acute leukemia patients and their prognostic significance. Pak. J. Pharmaceutical Sci., 29: 2405-2410. PMID: 28167485

Yang, M.A., G.V. Shurin, Z. Peiyuan and M.R. Shurin, 2013. Dendritic cells in the cancer microenvironment. J. Cancer, 4: 34-44. DOI: $10.7150 /$ jca. 5046

Yaqub, S. and E.M. Aandahl, 2009. Inflammation versus adaptive immunity in cancer pathogenesis. Critical Rev. Oncogenesis, 15: 43-63.

DOI: 10.1615/CritRevOncog.v15.i1-2.20
Yu, S., C. Liu, L. Zhang, B. Shan and T. Tian et al., 2014. Elevated Th22 cells correlated with Th17 cells in peripheral blood of patients with acute myeloid leukemia. Int. J. Molecular Sci., 15: 1927-1945. DOI: $10.3390 /$ ijms 15021927

Zamarron, B.F. and W.J. Chen, 2011. Dual roles of immune cells and their factors in cancer development and progression. Int. J. Biol. Sci., 7: 651-658. DOI: 10.7150/ijbs.7.651

Zediak, V.P., I. Maillard and A, Bhandoola, 2007. Multiple prethymic defects underlie age-related loss of $\mathrm{T}$ progenitor competence. Blood, 110: 1161-1167. DOI: 10.1182/blood-2007-01-071605

Zhang, P.Y., Y.J. Yang, C.M. Fu, L.L. Xiang and Q. Wang et al., 2015. Pathways involved in the evolution of leukemic stem cells. Eur. Rev. Med. Pharmacol. Sci., 19: 1356-1363. PMID: 25967709

Zhou, Q., M.E. Munger, R.G. Veenstra, B.J. Weigel and M. Hirashima et al., 2011. Co-expression of Tim-3 and PD-1 identifies a CD8 T-cell exhaustion phenotype in mice with disseminated acute myelogenous leukemia. Blood, 117: 4501-4510. DOI: 10.1182/blood-2010-10-310425

Zhou, Q., M.E. Munger, S.L. Highfill, J. Tolar and B.J. Weigel et al., 2010. Program death-1 signaling and regulatory $\mathrm{T}$ cells collaborate to resist the function of adoptively transferred cytotoxic $\mathrm{T}$ lymphocytes in advanced acute myeloid leukemia. Blood, 116: 2484-2493. DOI: 10.1182/blood-2010-03-275446 